\title{
Recruitment Maneuvers and PEEP Titration
}

\author{
Dean R Hess PhD RRT FAARC
}

\author{
Introduction \\ Physiologic Concepts \\ Stress and Strain \\ Potential for Recruitment \\ Stress, Strain, and Stress Raisers in the Context of Recruitment \\ Maneuvers and PEEP \\ Recruitment Maneuvers \\ Types of Recruitment Maneuvers \\ The Evidence \\ Summary and Recommendations: Recruitment Maneuvers \\ PEEP Titration \\ Gas Exchange \\ Compliance \\ Pressure-Volume Curve \\ Stress Index \\ Esophageal Manometry \\ Lung Volume \\ Imaging \\ How Long to Wait Between Changes in PEEP \\ Higher Versus Lower PEEP: The Evidence \\ Summary and Recommendation: PEEP \\ Summary
}

The injurious effects of alveolar overdistention are well accepted, and there is little debate regarding the importance of pressure and volume limitation during mechanical ventilation. The role of recruitment maneuvers is more controversial. Alveolar recruitment is desirable if it can be achieved, but the potential for recruitment is variable among patients with ARDS. A stepwise recruitment maneuver, similar to an incremental PEEP titration, is favored over sustained inflation recruitment maneuvers. Many approaches to PEEP titration have been proposed, and the best method to choose the most appropriate level for an individual patient is unclear. A PEEP level should be selected that balances alveolar recruitment against overdistention. The easiest approach to select PEEP might be according to the severity of the disease: $5-10 \mathrm{~cm} \mathrm{H}_{2} \mathrm{O}$ PEEP in mild ARDS, 10-15 $\mathrm{cm} \mathrm{H}_{2} \mathrm{O}$ PEEP in moderate ARDS, and 15-20 $\mathrm{cm} \mathrm{H}_{2} \mathrm{O}$ PEEP in severe ARDS. Recruitment maneuvers and PEEP should be used within the context of lung protection and not just as a means of improving oxygenation. Key words: ARDS; mechanical ventilation; PEEP; recruitment maneuver. [Respir Care 2015;60(11):1688-1704. (C) 2015 Daedalus Enterprises] 


\section{Recruitment Maneuvers and PEEP Titration}

\section{Introduction}

The respiratory mechanics of the lungs of patients with ARDS are characterized by their heterogeneity. Some alveoli are relatively normal, some are collapsed, some are fluid-filled, and some are consolidated (Fig. 1). This has given rise to the concept of a baby lung, ${ }^{1}$ suggesting that only a fraction of the lung is functional in ARDS. During positive-pressure ventilation, alveoli that are spared from the disease process are subject to overdistention (volutrauma). Alveoli that are collapsed are subject to repetitive opening and closing (opening during inspiration and collapse during expiration [atelectrauma]). ${ }^{2}$ The mechanisms, however, for the de-recruitment of dependent alveoli are controversial. Hubmayr ${ }^{3}$ has argued that the dependent lung may be de-recruited because it is filled with fluid, not because it is collapsed.

The injurious effects of alveolar overdistention have been well accepted since publication of the seminal ARDS Network study in $2000,{ }^{4}$ showing that ventilation at a target tidal volume $\left(\mathrm{V}_{\mathrm{T}}\right)$ of $6 \mathrm{~mL} / \mathrm{kg}$ of predicted body weight, similar to and often called ideal body weight, results in an important reduction in mortality, compared with a $\mathrm{V}_{\mathrm{T}}$ of $12 \mathrm{~mL} / \mathrm{kg}$ predicted body weight. The ARDS Network study led to the widespread recommendation of ventilation with $6 \mathrm{~mL} / \mathrm{kg}$ predicted body weight and a plateau pressure $\left(\mathrm{P}_{\text {plat }}\right) \leq 30 \mathrm{~cm} \mathrm{H}_{2} \mathrm{O}$. Subsequent studies have confirmed a survival benefit for low $V_{T}$ ventilation. ${ }^{5,6}$ Some studies have reported regional overdistention even with $\mathrm{P}_{\text {plat }}<30 \mathrm{~cm} \mathrm{H}_{2} \mathrm{O}$, suggesting that there might not be a safe $\mathrm{P}_{\text {plat }}{ }^{7,8}$ Thus, the lungs should be ventilated with $\mathrm{P}_{\text {plat }}$ as low as possible. Moreover, there is evidence supporting the use of a $\mathrm{V}_{\mathrm{T}}$ of $6 \mathrm{~mL} / \mathrm{kg}$ predicted body weight in all mechanically ventilated patients and suggesting that large $\mathrm{V}_{\mathrm{T}}$ might contribute to the development of ARDS. ${ }^{9}$ The use of conventional ventilation in patients with ARDS has been reviewed elsewhere. ${ }^{10-12}$

Although volume and pressure limitation has become well accepted as a lung-protective strategy, the roles of

Dr Hess is affiliated with Massachusetts General Hospital, Harvard Medical School, and Northeastern University, Boston, Massachusetts.

Dr Hess has disclosed relationships with Philips Respironics, Bayer, McGraw-Hill, Jones and Bartlett, UpToDate, and the American Board of Internal Medicine.

Dr Hess presented a version of this paper at the 30th New Horizons Symposium at the AARC Congress 2014, held December 10, 2014, in Las Vegas, Nevada.

Correspondence: Dean R Hess PhD RRT FAARC, Respiratory Care Services, Ellison 401, Massachusetts General Hospital, 55 Fruit Street, Boston, MA 02114. E-mail: dhess@mgh.harvard.edu

DOI: $10.4187 /$ respcare.04409 recruitment maneuvers and lower versus higher PEEP are more controversial. The purpose of this narrative review is to summarize the available literature related to this subject. Although this is not a systematic review or practice guideline, the intent is to provide a balanced review of the subject.

\section{Physiologic Concepts}

\section{Stress and Strain}

Stress is a force applied to an area, such as pressure applied to the alveolus (transalveolar pressure). Strain is the physical deformation, or change in shape, of an alveolus, caused by stress. Stress and strain can be described by the relationship, ${ }^{13}$

$P_{L}($ stress $)=$ specific lung elastance

$\times \Delta \mathrm{V} /$ functional residual capacity (strain),

where $\mathrm{P}_{\mathrm{L}}$ is the trans-alveolar pressure, and $\Delta \mathrm{V}$ is the change in lung volume above resting functional residual capacity with the addition of PEEP and $\mathrm{V}_{\mathrm{T}}$. Specific lung elastance (compliance per lung volume) is constant at $13.5 \mathrm{~cm} \mathrm{H}_{2} \mathrm{O}$. A harmful threshold of strain is $>2$. Thus, the harmful threshold of stress $\left(\mathrm{P}_{\mathrm{L}}\right)$ is $27 \mathrm{~cm} \mathrm{H}_{2} \mathrm{O}$, and lower values (eg, $\leq 20 \mathrm{~cm} \mathrm{H}_{2} \mathrm{O}$ ) are preferred.

A stress raiser is the result of inhomogeneity within the lungs where regions of collapse border regions of ventilation. ${ }^{13}$ Consider 2 adjacent alveoli fully expanded at a $\mathrm{P}_{\mathrm{L}}$ of $30 \mathrm{~cm} \mathrm{H}_{2} \mathrm{O}$. If one of the 2 regions collapses, the applied force concentrates in the other, thereby increasing its strain and stress. Mead et al ${ }^{14}$ calculated the result if the volume ratio of the 2 regions goes from 10:10 (ie, both regions distended) to 10:1 (one region distended and the other collapsed). Because the area is V/0.66, a volume ratio of $10: 1$ is equal to an area ratio of $(10 / 1) / 0.66$, or 4.57 , thereby increasing the stress of the open unit to $137 \mathrm{~cm} \mathrm{H}_{2} \mathrm{O}$. The stress of the open regions therefore increases from $30 \mathrm{~cm} \mathrm{H}_{2} \mathrm{O}$ to $137 \mathrm{~cm} \mathrm{H}_{2} \mathrm{O}$.

\section{Potential for Recruitment}

The benefit of recruitment maneuvers and PEEP might be related to the potential for alveolar recruitment in the lungs of patients with ARDS. Gattinoni et al ${ }^{15}$ tested the potential for recruitment in 68 subjects with ARDS using computed tomography (CT) of the lungs during breathholds at airway pressures of 5, 15, and $45 \mathrm{~cm} \mathrm{H}_{2} \mathrm{O}$. They defined the percentage of potentially recruitable lung as the proportion of lung tissue in which aeration was restored at airway pressures between 5 and $45 \mathrm{~cm} \mathrm{H}_{2} \mathrm{O}$. They found that the potential for recruitment varied widely. 


\section{Recruitment Maneuvers And PEEP Titration}

A
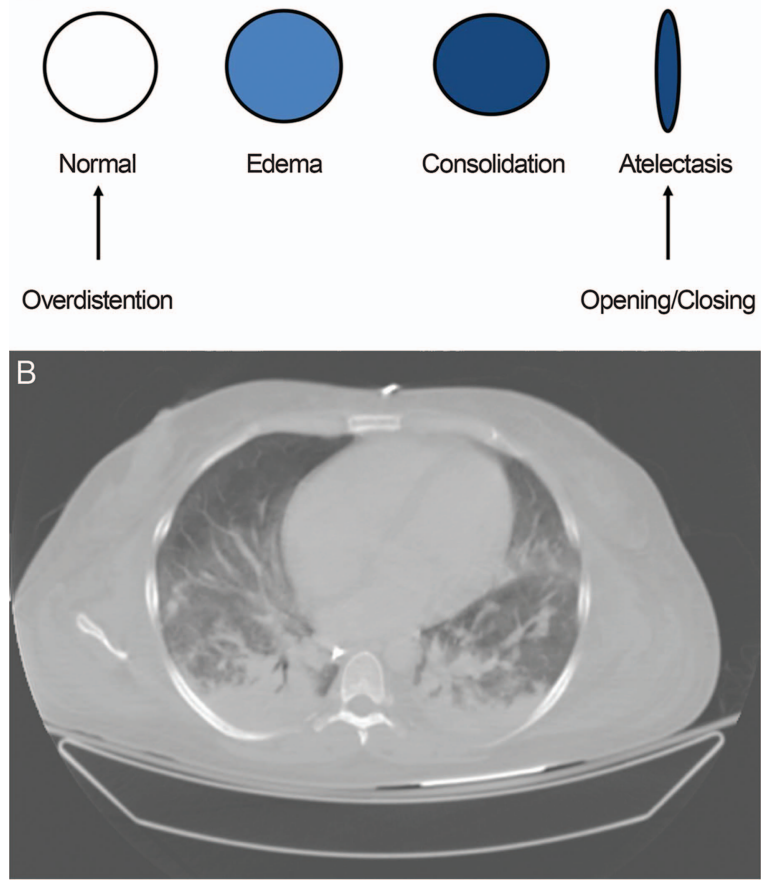

Fig. 1. A: Schematic representation of the heterogeneity of the lungs of patients with ARDS. Normal alveoli are subject to injury due to overdistention, whereas collapsed alveoli are subject to injury due to cyclic opening and closing throughout the respiratory cycle. B: Chest CT of a patient with ARDS. Note that the collapse and consolidation are primarily in the dependent lung zones. The nondependent regions appear relatively normal.

Subjects with a higher percentage of potentially recruitable lung had a lower $\mathrm{P}_{\mathrm{aO}_{2}} / \mathrm{F}_{\mathrm{IO}_{2}}$, lower compliance, and a higher dead-space fraction. $\mathrm{A} \mathrm{P}_{\mathrm{aO}_{2}} / \mathrm{F}_{\mathrm{IO}_{2}}<150$ at a PEEP of $5 \mathrm{~cm} \mathrm{H}_{2} \mathrm{O}$ and a decrease in dead space (ie, decrease in $\mathrm{P}_{\mathrm{aCO}_{2}}$ ) or an increase in compliance when PEEP was increased from 5 to $15 \mathrm{~cm} \mathrm{H}_{2} \mathrm{O}$ identified subjects with a greater potential for recruitment and thus might inform the use of recruitment maneuvers or higher levels of PEEP. Perhaps the most important finding from this study was that the lungs of some subjects with ARDS are highly recruitable, whereas others may have a low potential for recruitment.

The level of PEEP might affect $\mathrm{P}_{\mathrm{aO}_{2}} / \mathrm{F}_{\mathrm{IO}_{2}}$ and thus mask ARDS severity. ${ }^{16}$ Chiumello et al ${ }^{17}$ used wholelung $\mathrm{CT}$ to assess lung recruitability at the level of PEEP selected clinically $\left(11 \pm 3 \mathrm{~cm} \mathrm{H}_{2} \mathrm{O}\right)$, at $5 \mathrm{~cm} \mathrm{H}_{2} \mathrm{O}$, and at $15 \mathrm{~cm} \mathrm{H}_{2} \mathrm{O}$. Only when ARDS severity was classified at $5 \mathrm{~cm} \mathrm{H}_{2} \mathrm{O}$ PEEP did lung recruitability increase with severity; lung recruitability was greatest with severe ARDS $\left(\mathrm{P}_{\mathrm{aO}_{2}} / \mathrm{F}_{\mathrm{IO}_{2}} \leq 100\right)$ and least with mild ARDS $\left(\mathrm{P}_{\mathrm{aO}_{2}} / \mathrm{F}_{\mathrm{IO}_{2}}>200\right)$. The authors concluded that the Berlin definition assessed at $5 \mathrm{~cm} \mathrm{H}_{2} \mathrm{O}$ allows evaluation of lung recruitability.
Table 1. Methods to Achieve Alveolar Recruitment

Treatment of underlying disease process: removal of airway

obstruction, diuresis, treatment of infection

Sustained inflation followed by decremental PEEP

Stepwise recruitment (incremental PEEP)

Airway pressure release ventilation

High frequency oscillatory ventilation

Sigh

Prone positioning

\section{Stress, Strain, and Stress Raisers in the Context of Recruitment Maneuvers and PEEP}

The potential benefit or harm of recruitment maneuvers and PEEP can be illustrated physiologically through consideration of stress, strain, and stress raisers. In the setting of low potential for recruitment, an increase in alveolar pressure results in overdistention of already open alveoli, and this is magnified due to the effect of stress raisers. In this setting, $\mathrm{V}_{\mathrm{T}}$ should be reduced to as low as tolerated to decrease $\mathrm{P}_{\text {plat }}$ and minimize the effect of stress raisers. With low potential for alveolar recruitment, lower PEEP should be set. On the other hand, when there is a greater potential for recruitment, the addition of higher levels of PEEP results in alveolar stability and better homogeneity within the lungs. Because the volume is distributed to a larger number of alveoli, strain (and subsequently stress) is reduced. The greater number of open alveoli also reduces the effect of stress raisers. It thus follows that attempts at alveolar recruitment and higher PEEP might result in benefit or harm.

\section{Recruitment Maneuvers}

The application of low $\mathrm{V}_{\mathrm{T}}$ ventilation limits injury from alveolar overdistention. However, it does not address injury from repetitive alveolar opening and closing. A recruitment maneuver (Table 1) is a sustained increase in airway pressure with the goal to open collapsed alveoli, after which sufficient PEEP is applied to keep the lungs open. ${ }^{18}$ The goals of a recruitment maneuver are to serve as part of a lung protection strategy and to improve oxygenation. It should be appreciated that alveolar recruitment can be achieved without a recruitment maneuver per se. For example, removal of a mucous plug will promote recruitment of the distal lung, and a change in patient position might promote recruitment of previously collapsed alveoli. Although recruitment maneuvers have been in vogue among some clinicians, the advice of Hubmayr ${ }^{3}$ should be remembered: "Maximizing oxygen tension through the use of aggressive recruitment may be gratifying in the short-term, but at this point, who can say that it prevents lung injury and promotes alveolar repair?" 


\section{Recruitment Maneuvers and PEEP Titration}

\section{Types of Recruitment Maneuvers}

A sustained inflation is the recruitment maneuver that has probably been used most commonly. A common approach has been to set the ventilator to CPAP mode and increase the pressure to $30-40 \mathrm{~cm} \mathrm{H}_{2} \mathrm{O}$ for $30-40 \mathrm{~s}$ while monitoring the patient for signs of adverse effects, such as hemodynamic compromise. More aggressive techniques add pressure-controlled breaths during the PEEP increase (eg, pressure control of $10-20 \mathrm{~cm} \mathrm{H}_{2} \mathrm{O}$ with a breathing frequency of 10 breaths/min and an inspiration-expiration ratio of 1:1.) $)^{18}$ There was much enthusiasm for the use of recruitment maneuvers after the report by Amato et al ${ }^{19}$ of a survival benefit associated with an open lung strategy.

The ARDS Network investigated the use of recruitment maneuvers. ${ }^{20}$ In 69 subjects, they applied recruitment maneuvers (CPAP of 35-45 $\mathrm{cm} \mathrm{H}_{2} \mathrm{O}$ for $30 \mathrm{~s}$ ), compared with sham recruitment maneuvers (no change in ventilator settings). The responses to recruitment maneuvers were highly variable. In 10 instances, $\mathrm{S}_{\mathrm{pO}_{2}}$ increased by 5-9\% during the first $10 \mathrm{~min}$, but in 14 instances, $\mathrm{S}_{\mathrm{pO}_{2}}$ decreased by $1-4 \%$ after initiating the recruitment maneuver and did not return to baseline $\mathrm{S}_{\mathrm{pO}_{2}}$ within $10 \mathrm{~min}$. After $6 \mathrm{~h}$, respiratory system compliance increased significantly more after sham recruitment maneuvers. Hypotension and desaturation were more prevalent with the application of recruitment maneuvers than sham. Due to these results, the routine use of recruitment maneuvers was not continued in the ARDS Network studies.

Meade et $\mathrm{al}^{21}$ conducted a prospective multi-center physiologic study of sustained inflation recruitment maneuvers in 28 consecutive subjects with a $\mathrm{P}_{\mathrm{aO}_{2}} / \mathrm{F}_{\mathrm{IO}_{2}}<250$. A recruitment maneuver was applied at $35 \mathrm{~cm} \mathrm{H}_{2} \mathrm{O}$ for 20 s. If the initial response was unclear, a second recruitment maneuver at a pressure of $40 \mathrm{~cm} \mathrm{H}_{2} \mathrm{O}$ and then a third at $45 \mathrm{~cm} \mathrm{H}_{2} \mathrm{O}$ or for longer periods ( $30 \mathrm{~s}$ and then $40 \mathrm{~s}$ ) was applied. There was no net effect on oxygenation or pulmonary mechanics following the first or subsequent recruitment maneuvers. Augmenting the inflation pressure or duration had no significant effect. For the 122 recruitment maneuvers applied, 5 subjects developed ventilator asynchrony, 3 appeared uncomfortable, 2 experienced transient hypotension, and 4 developed barotrauma that required intervention. These results do not support the use of recruitment maneuvers in addition to usual care for ARDS.

A secondary analysis was performed by Fan et $\mathrm{al}^{22}$ of data from a randomized controlled trial of an open lung ventilation strategy that included sustained inflation recruitment maneuvers. Desaturation and hypotension from recruitment maneuvers occurred in $22 \%$ of all subjects, but new air leak through an existing chest tube was uncommon $(<5 \%)$. The number of recruitment maneuvers was associated with increased risk. The authors concluded that complications related to recruitment maneuvers were com- mon, but serious complications were infrequent. They recommended that, given their uncertain benefit and the potential for complications with repeated application, the routine use of sustained inflation recruitment maneuvers is not justified.

The optimal duration of a sustained inflation recruitment maneuver in subjects with ARDS was evaluated by Arnal et al, ${ }^{23}$ who applied a $40-\mathrm{cm} \mathrm{H}_{2} \mathrm{O}$ sustained inflation for $30 \mathrm{~s}$ in 50 subjects within the first $24 \mathrm{~h}$ of meeting ARDS criteria. They found that most of the recruitment occurs during the first $10 \mathrm{~s}$ of the maneuver, but hemodynamic impairment was significant after $10 \mathrm{~s}$ of initiation.

An approach that has been advocated is application of a recruitment maneuver followed by a decremental PEEP titration (open lung approach). ${ }^{24}$ With this approach, a recruitment maneuver is applied, after which the PEEP is set at a high level (eg, 20-25 $\mathrm{cm} \mathrm{H}_{2} \mathrm{O}$ ). PEEP is then decreased in 2-cm $\mathrm{H}_{2} \mathrm{O}$ decrements, and the compliance is measured at each step to determine best compliance. Others have used arterial oxygenation ${ }^{25-27}$ or dead space ${ }^{28}$ rather than compliance to identify best PEEP during the decremental PEEP titration. After using either compliance or oxygenation to identify the pressure at which recruitment is not maintained, the recruitment maneuver is then repeated, after which PEEP is set $2 \mathrm{~cm} \mathrm{H}_{2} \mathrm{O}$ greater than the level identified as best compliance.

In a provocative editorial, Marini ${ }^{29}$ suggests that there are good reasons to retire the sustained inflation recruitment maneuver from clinical practice. In its place, he suggests that stepwise approaches are perhaps more effective than abrupt applications of the same peak pressure. Moreover, the graded rise of pressure is better tolerated from a hemodynamic standpoint. In his words, "clinicians are well advised to relegate this once useful clinical tool to the growing archive of historically instructive but now obsolete methodologies."

An example of a stepwise recruitment maneuver is shown in Figure 2. This approach utilizes an incremental PEEP titration and balances recruitment against overdistention. PEEP is increased in increments of $2-5 \mathrm{~cm} \mathrm{H}_{2} \mathrm{O}$ with a fixed $\mathrm{V}_{\mathrm{T}}$ of $6 \mathrm{~mL} / \mathrm{kg}$ ideal body weight using volume control ventilation. Driving pressure $\left(\mathrm{P}_{\text {plat }}-\mathrm{PEEP}\right)$, compliance, $\mathrm{S}_{\mathrm{pO}_{2}}$, and blood pressure are monitored at each step. PEEP is increased if there is evidence of recruitment: decreased driving pressure, $\mathrm{P}_{\text {plat }}<30 \mathrm{~cm} \mathrm{H}_{2} \mathrm{O}$, or increased $\mathrm{S}_{\mathrm{pO}_{2}}$. PEEP (or perhaps $\mathrm{V}_{\mathrm{T}}$ ) is decreased to the previous step if there are indications of overdistention: increased driving pressure, $\mathrm{P}_{\text {plat }}>30 \mathrm{~cm} \mathrm{H}_{2} \mathrm{O}$, hypotension, or decreased $\mathrm{S}_{\mathrm{PO}_{2}}$. Each step is 3-5 min unless there is an adverse effect (hypotension, desaturation) that prompts a decrease in PEEP to the previous step. An alternative approach uses a fixed level of pressure control as the PEEP is increased; evidence is lacking that one approach is bet- 


\section{Recruitment Maneuvers And PEEP Titration}
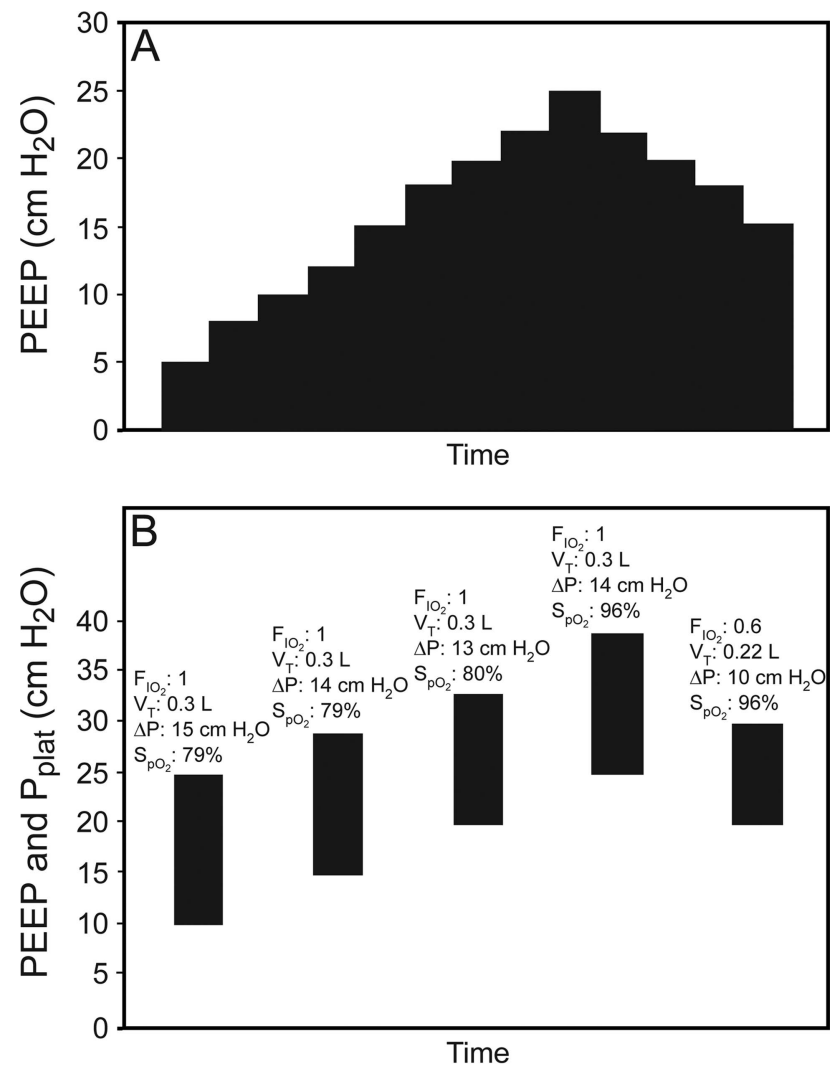

Fig. 2. A: Schematic representation of a stepwise recruitment maneuver. B: An example of a stepwise recruitment maneuver in a patient with severe ARDS due to H1N1 infection. When PEEP is increased to $25 \mathrm{~cm} \mathrm{H}_{2} \mathrm{O}$, there is an improvement in $\mathrm{S}_{\mathrm{pO}_{2}}$, but the $\mathrm{P}_{\text {plat }}$ is unacceptably high. The PEEP and tidal volume are decreased so that the $\mathrm{P}_{\text {plat }}$ and driving pressure are acceptable. The PEEP was increased every 2-5 min.

ter than the other, and the choice is determined by individual bias.

Several ventilator modes are used to promote alveolar recruitment. Airway pressure release ventilation allows patients to breathe spontaneously while receiving high airway pressure with an intermittent pressure release. The high pressure is used for alveolar recruitment. By promoting spontaneous breathing, it might improve alveolar recruitment to the dorsal caudal regions of the lungs. ${ }^{30} \mathrm{Al}-$ though arterial oxygenation might be better with airway pressure release ventilation, evidence is lacking to support improved outcomes. ${ }^{31-33}$ Given that the trans-alveolar distending pressures are probably high during spontaneous breathing with airway pressure release ventilation, the potential for lung injury is of concern. ${ }^{34}$

High frequency oscillatory ventilation (HFOV) has also been used to increase airway pressure and promote alveolar recruitment. It was hoped that the delivery of a small $\mathrm{V}_{\mathrm{T}}$ and a high mean airway pressure with HFOV would improve alveolar recruitment with less risk of overdistention. A survival benefit, however, has not been demon- strated with HFOV. In one randomized clinical trial, Young et $\mathrm{al}^{35}$ found no significant difference between conventional ventilation and HFOV. Ferguson et al ${ }^{36}$ randomly assigned adults with new-onset, moderate to severe ARDS to HFOV or to a control strategy targeting lung recruitment with the use of low $\mathrm{V}_{\mathrm{T}}$ and high PEEP. The study was stopped early with an in-hospital mortality of $47 \%$ in the HFOV group, compared with $35 \%$ in the control group (relative risk of death with HFOV 1.33, 95\% CI 1.09 1.64). These studies bring into question whether HFOV is a viable approach in adults with ARDS. ${ }^{37}$

A sigh function was available on ventilators in the 1970s and 1980s. But interest in the use of sigh diminished, and this feature was removed from many ventilators. Interest in the use of sigh has reemerged, particularly in patients ventilated with pressure support. Periodic sighs can be provided using modes such as the PCV + mode (called biphasic positive airway pressure in Europe) of the Dräger ventilator or the BiLevel mode of the Puritan-Bennett 840 or 980 ventilators. Several studies have evaluated the effect of sighs. ${ }^{38-42}$ In the most recent of these, Mauri et al ${ }^{42}$ examined the effect of adding a sigh to pressure-support ventilation in 20 critically ill subjects with a $\mathrm{P}_{\mathrm{aO}_{2}} / \mathrm{F}_{\mathrm{IO}_{2}}$ $<300$. They used biphasic positive airway pressure at $35 \mathrm{~cm} \mathrm{H}_{2} \mathrm{O}$ for 3-4 s at rates of $2 \mathrm{sighs} / \mathrm{min}, 1 \mathrm{sigh} / \mathrm{min}$, and $1 \mathrm{sigh} / 2 \mathrm{~min}$. The pressure support level was $8 \pm 2 \mathrm{~cm} \mathrm{H}_{2} \mathrm{O}$, PEEP was $8 \pm 2 \mathrm{~cm} \mathrm{H}_{2} \mathrm{O}$, and $\mathrm{F}_{\mathrm{IO}_{2}}$ was $0.5 \pm 0.1$. Global and regional end-expiratory lung volume were estimated using electrical impedance tomography. With sigh, $\mathrm{P}_{\mathrm{aO}_{2}}$ improved (from $85 \mathrm{~mm} \mathrm{Hg}$ to $108 \mathrm{~mm} \mathrm{Hg}$ on average). Sigh-induced alveolar recruitment of previously collapsed regions occurred both in dependent and nondependent lung zones, suggesting that it might result in more homogeneous distribution of tidal ventilation. A limitation of this study is that the authors only evaluated the effects of sigh; whether similar results would have occurred with an increase in PEEP is unknown.

Prone positioning promotes recruitment of non-aerated alveoli, which results in improved oxygenation and makes the lung more homogeneous. ${ }^{43-45}$ Prone position may reduce lung stress and strain in severe ARDS. Thus, prone positioning might be considered a recruitment maneuver. ${ }^{46}$ One randomized controlled trial ${ }^{47}$ and several meta-analyses report a survival benefit for prone position, ${ }^{48,49}$ particularly in severe ARDS. ${ }^{43}$

\section{The Evidence}

Despite the clinical and academic interest in recruitment maneuvers, most of the studies have been physiologic assessments, and there have been few outcome studies. In the open lung approach of Amato et al, ${ }^{19}$ recruitment maneuvers were a CPAP of $35-40 \mathrm{~cm} \mathrm{H}_{2} \mathrm{O}$ applied for $40 \mathrm{~s}$. 


\section{Recruitment Maneuvers and PEEP Titration}

Although this study included recruitment maneuvers as part of a lung-protective ventilation strategy that resulted in better patient outcomes, the contribution of recruitment maneuvers to the other interventions is unclear. Villar et al ${ }^{50}$ conducted a study similar to that of Amato et al ${ }^{19}$, except that they did not use recruitment maneuvers as used in the Amato et al ${ }^{19}$ study. Interestingly, they found that a mechanical ventilation strategy with higher PEEP and lower $\mathrm{V}_{\mathrm{T}}$ had a beneficial impact on outcome in patients with severe ARDS, this without the use of a recruitment maneuver per se.

Meade et al ${ }^{51}$ compared a low- $\mathrm{V}_{\mathrm{T}}$ ventilation strategy with an open-lung approach, which combined low $\mathrm{V}_{\mathrm{T}}$, recruitment maneuvers, and high PEEP. Unlike in the paper by Amato et al, ${ }^{19}$ the open lung approach resulted in no significant difference in hospital mortality compared with a low- $\mathrm{V}_{\mathrm{T}}$ ventilation strategy, although it did improve secondary end points related to hypoxemia and the use of rescue therapies. Hodgson et al ${ }^{52}$ conducted a randomized controlled trial comparing an open lung strategy with a stepwise recruitment maneuver with a PEEP strategy using the ARDS Network PEEP/ $/ \mathrm{IO}_{2}$ table. ${ }^{4}$ There were only 10 subjects in each group, however, which makes difficult any meaningful interpretation.

Suzumura et $\mathrm{al}^{53}$ conducted a meta-analysis to assess the effects of recruitment maneuvers on clinical outcomes in subjects with ARDS. Their review identified 10 randomized controlled trials of 1,594 subjects. For the outcome of in-hospital mortality, the meta-analysis found a risk ratio of 0.84 (95\% CI 0.74-0.95). However, the quality of evidence was considered low because recruitment maneuvers were usually conducted together with other ventilatory interventions, making it difficult to isolate the effect of the recruitment maneuvers per se. There were no differences in the rates of barotrauma or the need for rescue therapies. There was no effect of recruitment maneuvers in terms of duration of mechanical ventilation, ICU stay, and hospital stay. When considering only studies with a low risk of bias, there was no significant effect of recruitment maneuvers on mortality (risk ratio $0.90,95 \% \mathrm{CI}$ $0.78-1.04)$. Perhaps the greatest issue with this meta-analysis is the considerable heterogeneity in how individual studies were conducted, such as the specific method used to perform the recruitment maneuver and the method used to set PEEP after the recruitment maneuver. The authors correctly conclude that, although recruitment maneuvers may decrease the mortality of patients with ARDS, the currently available evidence is not definitive.

\section{Summary and Recommendations: Recruitment Maneuvers}

1. Evidence is lacking that the use of recruitment maneuvers improves patient outcomes.
Table 2. Methods for Setting PEEP in Patients With ARDS
Gas exchange
Compliance
Pressure-volume curve
Stress index
Esophageal manometry
Lung volume
Imaging

2. Alveolar recruitment is desirable if it can be achieved safely, but there is variable potential for recruitment among patients with ARDS.

3. A stepwise recruitment maneuver is preferred over sustained inflation.

4. Complications of recruitment such as hypotension and desaturation are common but temporary; complications such as barotrauma appear to be rare.

5. If a recruitment maneuver is effective, sufficient PEEP is necessary to maintain the recruitment.

6. Evidence is not sufficient to recommend the routine use of recruitment maneuvers as standard practice.

\section{PEEP Titration}

In the first clinical description of ARDS, Ashbaugh et $\mathrm{al}^{54}$ reported their use of PEEP in 5 subjects as a "therapeutic trial of apparent value." Soon thereafter, Downs et $a^{55}$ reported their experience with incremental PEEP titration on $\mathrm{P}_{\mathrm{aO}_{2}}$, suggesting that PEEP should be increased to obtain optimal $\mathrm{P}_{\mathrm{aO}_{2}}$ without hemodynamic compromise. This led to the recommendation of Kirby et al ${ }^{56}$ to use very high levels of PEEP to effect the greatest reduction in shunt fraction. These super high levels of PEEP (as high as $44 \mathrm{~mm} \mathrm{Hg}\left[60 \mathrm{~cm} \mathrm{H}_{2} \mathrm{O}\right]$ ) most assuredly resulted in overdistention of some parts of the lungs.

Setting PEEP appropriately is now recognized as an important aspect of a lung-protective ventilation strategy and not just a strategy to improve oxygenation. Setting PEEP levels $<5 \mathrm{~cm} \mathrm{H}_{2} \mathrm{O}$ may be harmful in the acute phase of ARDS. ${ }^{57}$ Setting PEEP appropriately is a balance between maintaining alveolar recruitment and avoiding alveolar overdistention. There are several methods that have been proposed for PEEP titration in an individual patient with ARDS (Table 2). Although non-respiratory adverse effects of PEEP are important (eg, hemodynamic, renal, neurologic), this review will focus on respiratory effects.

\section{Gas Exchange}

Oxygenation is a commonly used target when selecting PEEP for a patient with ARDS. However, this physiologic target should be viewed with some caution. Goligher et al ${ }^{58}$ 


\section{Recruitment Maneuvers and PEEP Titration}

conducted a secondary analysis of the Lung Open Ventilation study ${ }^{51}$ and the ExPress ${ }^{63}$ study to examine the relationship between the initial response to changes in PEEP after randomization and mortality. An increase in $\mathrm{P}_{\mathrm{aO}_{2}} / \mathrm{F}_{\mathrm{IO}_{2}}$ when PEEP was increased was associated with reduced mortality (OR $0.80,95 \%$ CI $0.72-0.89$ ) for an increase of 25 in $\mathrm{P}_{\mathrm{aO}_{2}} / \mathrm{F}_{\mathrm{IO}_{2}}$, particularly in subjects with a $\mathrm{P}_{\mathrm{aO}} / \mathrm{F}_{\mathrm{IO}_{2}}$ $\leq 150$. A decrease in $\mathrm{P}_{\mathrm{aO}_{2}} / \mathrm{F}_{\mathrm{IO}_{2}}$ after an increase in PEEP was associated with an increase in mortality (Fig. 3). The $\mathrm{P}_{\mathrm{aO}} / \mathrm{F}_{\mathrm{IO}_{2}}$ response after decreased or unchanged PEEP was not associated with mortality. These results suggest that improved oxygenation after an increase in PEEP might be associated with a lower risk of death. Thus, the oxygenation response to PEEP might be used to predict whether an individual patient will benefit from a higher versus a lower PEEP setting.

Combinations of PEEP and $\mathrm{F}_{\mathrm{IO}_{2}}$ to maintain a targeted $\mathrm{S}_{\mathrm{pO}_{2}}(88-95 \%)$ or $\mathrm{P}_{\mathrm{aO}_{2}}(55-80 \mathrm{~mm} \mathrm{Hg})$ have been used in the ARDS Network studies (Fig. 4).59 These tables are criticized because they do not target the PEEP

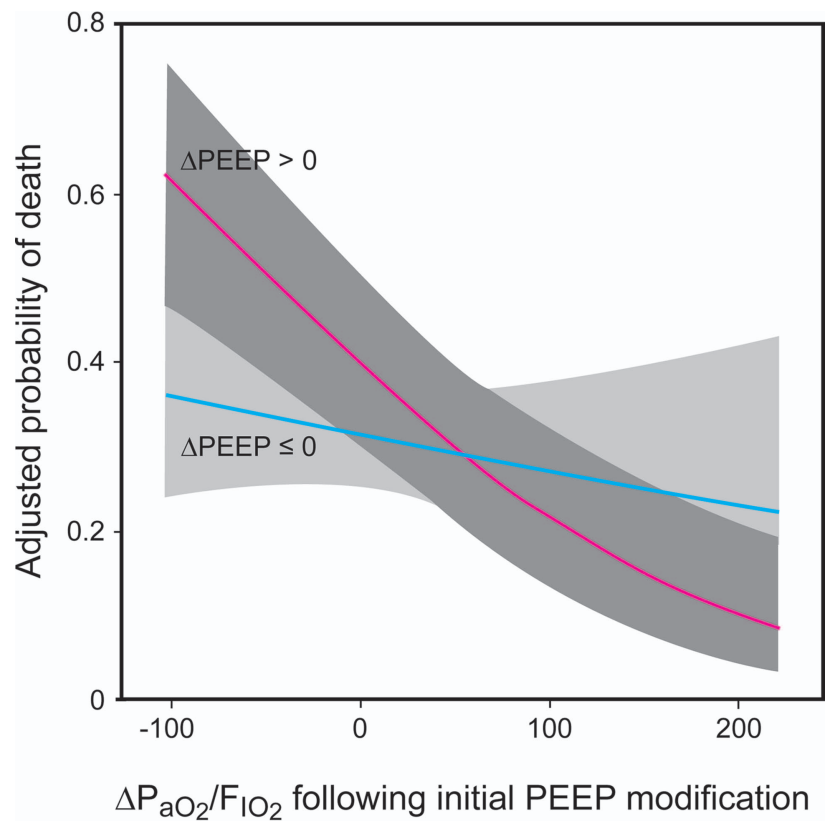

Fig. 3. The relationship between oxygenation response and mortality depends on whether the PEEP was increased. Changes in oxygenation after increased PEEP are strongly associated with adjusted mortality, whereas changes in oxygenation with decreased or unchanged PEEP are not associated with adjusted mortality. Shaded zones represent $95 \%$ confidence intervals. From Reference 58, with permission. level to individual lung mechanics and because they are based on expert opinion rather than empiric evidence. They are, however, very easy to apply at the bedside and have the face validity of having been used in all of the ARDS Network studies. One of the tables is more aggressive in the approach to PEEP than the other. Given that the lungs of patients with more severe ARDS are likely to be more recruitable and given evidence for better outcomes with higher PEEP in moderate and severe ARDS, it would be reasonable to use the lower PEEP table strategy for mild ARDS (less potential for recruitment) and the higher PEEP table strategy for moderate and severe ARDS (greater potential for recruitment). ${ }^{12}$ Intellivent is a ventilator mode that incorporates the ARDS Network tables into the ventilator software. ${ }^{60-62}$

$\mathrm{PEEP} / \mathrm{F}_{\mathrm{IO}_{2}}$ tables were also used in the Lung Open Ventilation study, ${ }^{51}$ very similar to those used by the ARDS Network. In 51 subjects, Chiumello et al ${ }^{17}$ compared the use of this table against 3 other approaches for setting PEEP: compliance, ${ }^{63}$ stress index,${ }^{64}$ and esophageal manometry. ${ }^{65}$ Lung recruitability was assessed by whole-lung CT scans taken in static conditions at 5 and $45 \mathrm{~cm} \mathrm{H}_{2} \mathrm{O}$ during an end-expiratory and end-inspiratory pause. Only the Lung Open Ventilation study table resulted in PEEP levels related to lung recruitability, with a progressive increase from mild to moderate and severe ARDS (Fig. 5). This provides physiologic support for the use of a PEEP/F $/ \mathrm{IO}_{2}$ table, such as those used by the ARDS Network or the Lung Open Ventilation study.

The appropriate level of PEEP should correspond to the lowest dead-space fraction $\left(\mathrm{V}_{\mathrm{D}} / \mathrm{V}_{\mathrm{T}}\right)$, as has been reported many years ago by Suter et al ${ }^{66}$ and more recently by Fengnei et al ${ }^{28}$ Because end-tidal $\mathrm{P}_{\mathrm{CO}_{2}}\left(\mathrm{P}_{\mathrm{ETCO}_{2}}\right)$ is determined, in part, by $\mathrm{V}_{\mathrm{D}} / \mathrm{V}_{\mathrm{T}}$, there has been interest in the use of capnography to assess best PEEP. In an experimental model of ARDS, Murray et al ${ }^{67}$ reported that best PEEP was associated with the smallest difference between $\mathrm{P}_{\mathrm{aO}_{2}}$ and $\mathrm{P}_{\mathrm{ETCO}_{2}}$. Subsequent clinical studies, ${ }^{68,69}$ however, have had mixed results, and thus $\mathrm{P}_{\mathrm{ETCO}}$ is not commonly used to determine best PEEP.

Mainstream capnography measures $\mathrm{CO}_{2}$ excretion. Theoretically, an increase in PEEP that causes overdistention will disrupt the steady-state balance between $\mathrm{CO}_{2}$ production and $\mathrm{CO}_{2}$ excretion. ${ }^{70}$ This is due to the

\section{Lower PEEP/Higher $\mathrm{F}_{\mathrm{IO}_{2}}$ \\ $\mathrm{F}_{\mathrm{IO}_{2}}$ \\ PEEP \\ Higher PEEP/Lower $\mathrm{F}_{\mathrm{IO}_{2}}$ \\ $\begin{array}{llllllllllllll}0.3 & 0.4 & 0.4 & 0.5 & 0.5 & 0.6 & 0.7 & 0.7 & 0.7 & 0.8 & 0.9 & 0.9 & 0.9 & 1.0\end{array}$

$\begin{array}{llllllllllllll}5 & 5 & 8 & 8 & 10 & 10 & 10 & 12 & 14 & 14 & 14 & 16 & 18 & 18-24\end{array}$

$\begin{array}{lllllllllllllll}0.3 & 0.3 & 0.3 & 0.3 & 0.3 & 0.4 & 0.4 & 0.5 & 0.5 & 0.5-0.8 & 0.8 & 0.9 & 0.9 & 1.0 & 1.0 \\ 5 & 8 & 10 & 12 & 14 & 14 & 16 & 16 & 18 & 20 & 22 & 22 & 22 & 22 & 24\end{array}$

Fig. 4. Tables used to set combinations of $\mathrm{F}_{\mathrm{IO}_{2}}$ and PEEP in the ARDS Network study. Data from Reference 59. 


\section{Recruitment Maneuvers And PEEP Titration}

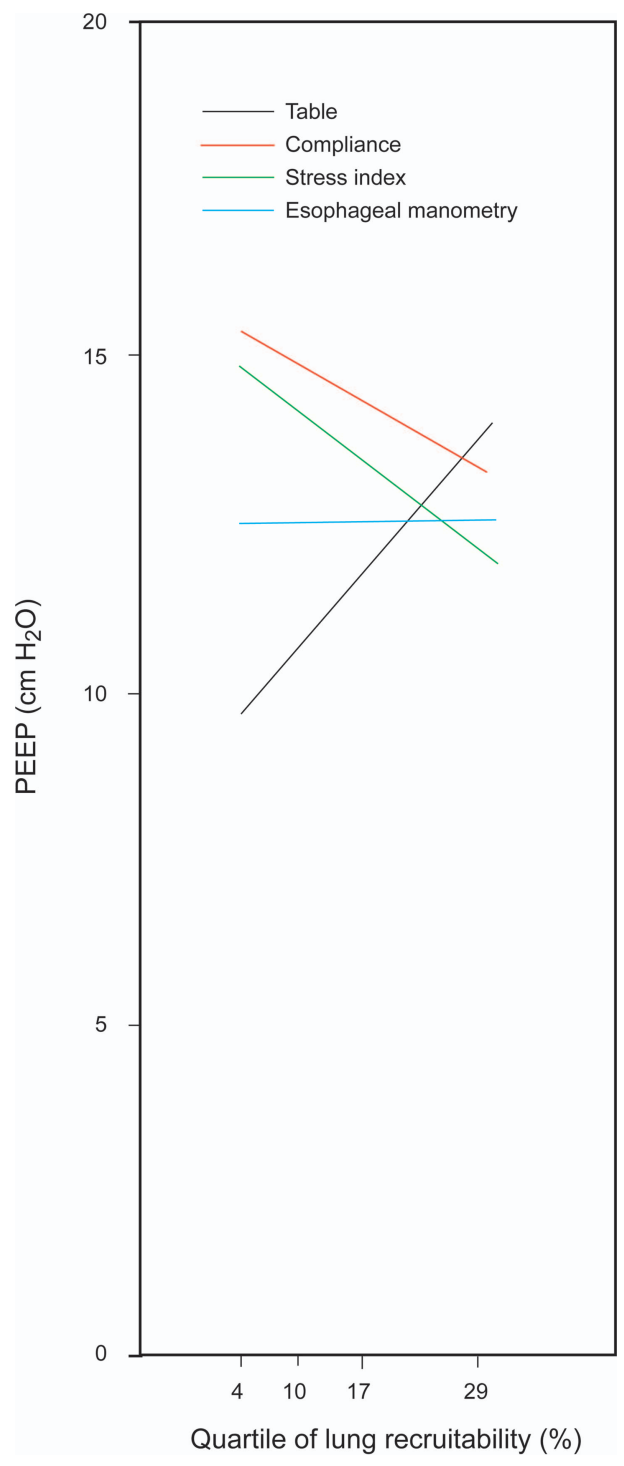

Fig. 5. Relationship between the average PEEP and end-expiratory transpulmonary pressure levels selected with the 4 bedside methods and lung recruitment. From Reference 17, with permission.

effects of overdistention on dead space and on venous return. Thus, there should be a temporary decrease in $\mathrm{CO}_{2}$ excretion until a new steady state is reached. This physiologic effect of PEEP has not been well studied, and thus the use of $\mathrm{CO}_{2}$ excretion during PEEP titration is not commonly used.

\section{Compliance}

A common approach used to determine optimum PEEP is based on incremental or decremental PEEP titration and selecting the level of PEEP with the highest compliance. Suter et al ${ }^{66}$ first described this in 1975 . They conducted a physiologic study of 15 subjects in acute respiratory failure; because some subjects were reported to be breathing an $\mathrm{F}_{\mathrm{IO}_{2}}$ of 0.21 , presumably some did not have ARDS. They made a number of physiologic measurements as they conducted an incremental PEEP titration from 0 to the level at which there was a marked decrease in cardiac output. $\mathrm{V}_{\mathrm{T}}$ was set at $13-15 \mathrm{~mL} / \mathrm{kg}$ (the authors do not indicate whether this was ideal body weight or actual body weight). They found that the PEEP corresponding to maximum oxygen delivery corresponded to the lowest $\mathrm{V}_{\mathrm{D}} / \mathrm{V}_{\mathrm{T}}$ and the highest compliance. The best PEEP varied from 0 to $15 \mathrm{~cm} \mathrm{H}_{2} \mathrm{O}$ among subjects.

Pintado et $\mathrm{al}^{71}$ evaluated the effect of setting PEEP at the highest compliance on oxygenation, multiple-organ dysfunction, and survival in subjects with ARDS. $V_{T}$ was set at $6-8 \mathrm{~mL} / \mathrm{kg}$ ideal body weight, and $\mathrm{P}_{\text {plat }}$ was maintained $<30 \mathrm{~cm} \mathrm{H}_{2} \mathrm{O}$. Subjects were randomized to PEEP titration using the low $\mathrm{PEEP} / \mathrm{F}_{\mathrm{IO}_{2}}$ table of the ARDS Network or compliance-guided PEEP. For the compliance group, PEEP was increased in steps of $2 \mathrm{~cm} \mathrm{H}_{2} \mathrm{O}$, beginning at $5 \mathrm{~cm} \mathrm{H}_{2} \mathrm{O}$ and without an upper limit. PEEP was adjusted once daily in the morning. Subjects in the compliance-guided group had a lower 28 -d mortality ( $20.6 \%$ vs $38.9 \%$ ), although this did not reach statistical significance due to the small sample size $(n=70)$. Multiple-organ dysfunction-free days (median 6 vs $20.5 \mathrm{~d}$, respiratory failure-free days (median $7.5 \mathrm{vs} 14.5 \mathrm{~d}$ ), and hemodynamic failure-free days (median 16 vs 22 d) at $28 \mathrm{~d}$ were significantly lower in subjects with a compliance-guided setting of PEEP. In a physiologic study, Fengmei et $\mathrm{al}^{28}$ reported that, using an open lung approach and decremental PEEP titration, best PEEP was similar for highest compliance and lowest $\mathrm{V}_{\mathrm{D}} / \mathrm{V}_{\mathrm{T}}$.

The randomized controlled trial by Mercat et al ${ }^{63}$ compared a low PEEP strategy of 5-9 $\mathrm{cm} \mathrm{H}_{2} \mathrm{O}(n=382)$ with a PEEP strategy set to reach a $\mathrm{P}_{\text {plat }}$ of $28-30 \mathrm{~cm} \mathrm{H}_{2} \mathrm{O}$ $(n=385)$. The maximum $\mathrm{P}_{\text {plat }}$ strategy is essentially a best compliance, or lowest driving pressure, strategy because a higher PEEP for the same $\mathrm{P}_{\text {plat }}$ means that $\mathrm{P}_{\text {plat }}$ - PEEP must be lower. Although 28-d mortality was not different between groups, the $\mathrm{P}_{\text {plat }}$ group did have better lung function and a shorter duration of mechanical ventilation.

A recent analysis of data from 9 randomized controlled trials $(\mathrm{N}=3,562$ subjects with ARDS) evaluated the relationships between driving pressure $\left(\mathrm{P}_{\text {plat }}-\mathrm{PEEP}\right)$ and mortality. ${ }^{72}$ Driving pressure is the denominator of the compliance equation: compliance $=\mathrm{V}_{\mathrm{T}} /\left(\mathrm{P}_{\text {plat }}-\right.$ PEEP $)$. The results of this post hoc analysis suggest an increased risk in mortality for driving pressure $>15 \mathrm{~cm} \mathrm{H}_{2} \mathrm{O}$. This has implications for PEEP titration. If an increase in PEEP results in overdistention, driving pressure will increase with a potential increased risk of mortality. On the other hand, if an increase in PEEP results in 


\section{Recruitment Maneuvers AND PEEP Titration}

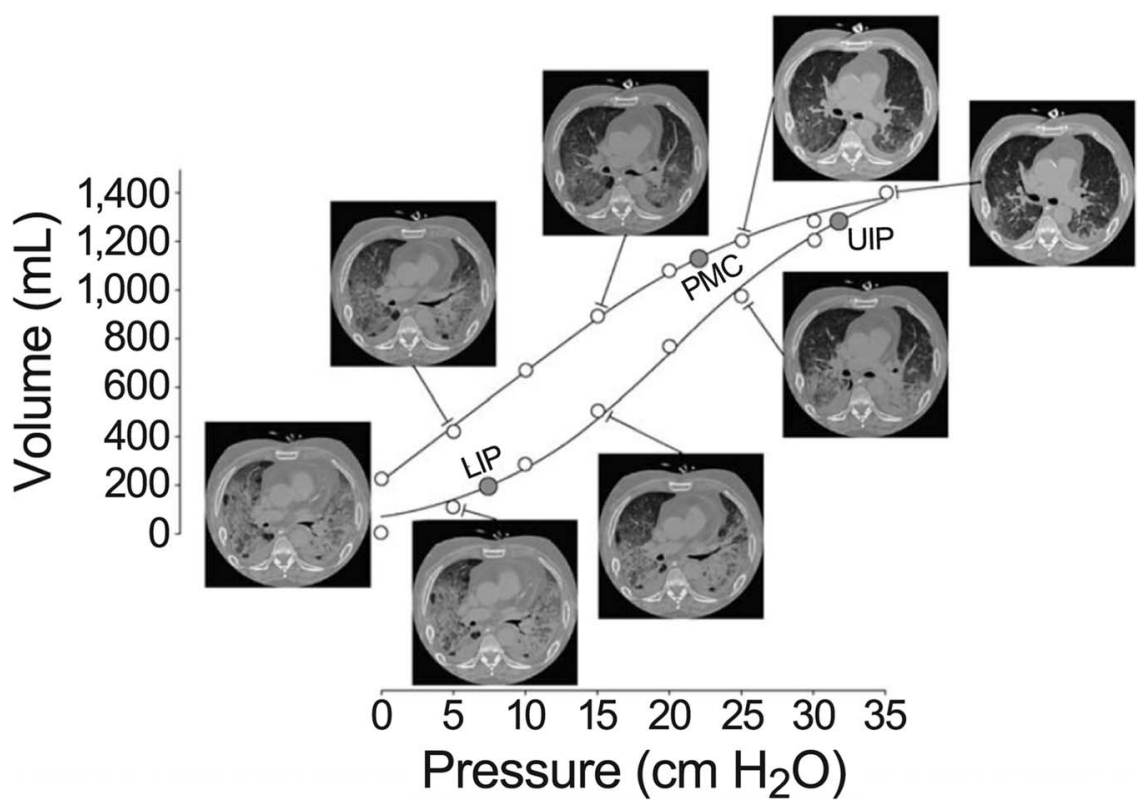

Fig. 6. Lung CT images were obtained while tracing the curve in static conditions. Note that recruitment only starts when airway pressure is higher than the lower inflection point (LIP) of the inspiratory limb and continues up to the maximum pressure reached, even above the upper inflection point (UIP). There is, however, no de-recruitment when airway pressure decreases from this level to the expiratory point of maximum curvature (PMC). With pressures below this point, de-recruitment starts and continues along the rest of the expiratory limb of the curve. From Reference 73, with permission.

recruitment and improved compliance, the driving pressure will decrease, which might afford a survival benefit.

\section{Pressure-Volume Curve}

The pressure-volume (P-V) curve displays the relationship between volume and pressure as the lungs are inflated and deflated (Fig. 6). ${ }^{74}$ It can be measured with a supersyringe, constant slow inflation $(<10 \mathrm{~L} / \mathrm{min})$, or measurement of $\mathrm{P}_{\text {plat }}$ at various inflation volumes. ${ }^{75}$ Correct interpretation of the $\mathrm{P}-\mathrm{V}$ curve during non-constant flow ventilation (eg, pressure-controlled ventilation), during spontaneous breathing, and with high inspiratory flows is problematic. Some ventilators measure the P-V curve with a constant slow inflation, and some are able to measure both inflation and deflation curves.

Amato et al $^{19}$ popularized an approach for setting PEEP based upon the P-V curve and identification of lower and upper inflection points. The lower inflection point is thought to represent the pressure at which a large number of alveoli are recruited, and Amato et al ${ }^{19}$ recommended that PEEP be set $2 \mathrm{~cm} \mathrm{H}_{2} \mathrm{O}$ above this pressure. An upper inflection point on the $\mathrm{P}-\mathrm{V}$ curve might indicate overdistention, or, alternatively, it might represent the end of recruitment.

Despite prior enthusiasm for the use of $\mathrm{P}-\mathrm{V}$ curves to set the ventilator in patients with ARDS, a number of issues preclude routine use. Correct P-V curve measurement requires sedation and often paralysis. It is often difficult to identify the inflection points, and precise identification may require mathematical curve fitting. ${ }^{76}$ Esophageal pressure measurement is needed to separate lung from chest wall effects. ${ }^{77}$ Although the inflation limb of the P-V curve is most commonly measured, the deflation limb may be more useful. Because the P-V curve treats the lungs as a single compartment and because the lungs of patients with ARDS are heterogeneous, recruitment has been shown to occur along the entire inflation P-V curve. ${ }^{73}$ The shape of the P-V curve might not be related to recruitment and might be explained by other mechanisms, such as inflation of an edematous lung. ${ }^{3}$

One approach to setting PEEP is to perform a recruitment maneuver followed by a decremental PEEP titration. ${ }^{78}$ The intent is to shift ventilation from the inflation limb to the deflation limb of the P-V curve. This results in a greater lung volume for the same applied PEEP. Although this is theoretically attractive, whether it affects important patient outcomes is unclear. Performing P-V curves and measuring lung volume corresponding to different PEEP levels can assess PEEP-induced lung recruitment. Lung recruitment at a given airway pressure is the difference in lung volume between P-V curves starting at different end-expiratory lung volumes corresponding to different levels of PEEP. ${ }^{73}$ 


\section{Recruitment Maneuvers and PEEP Titration}
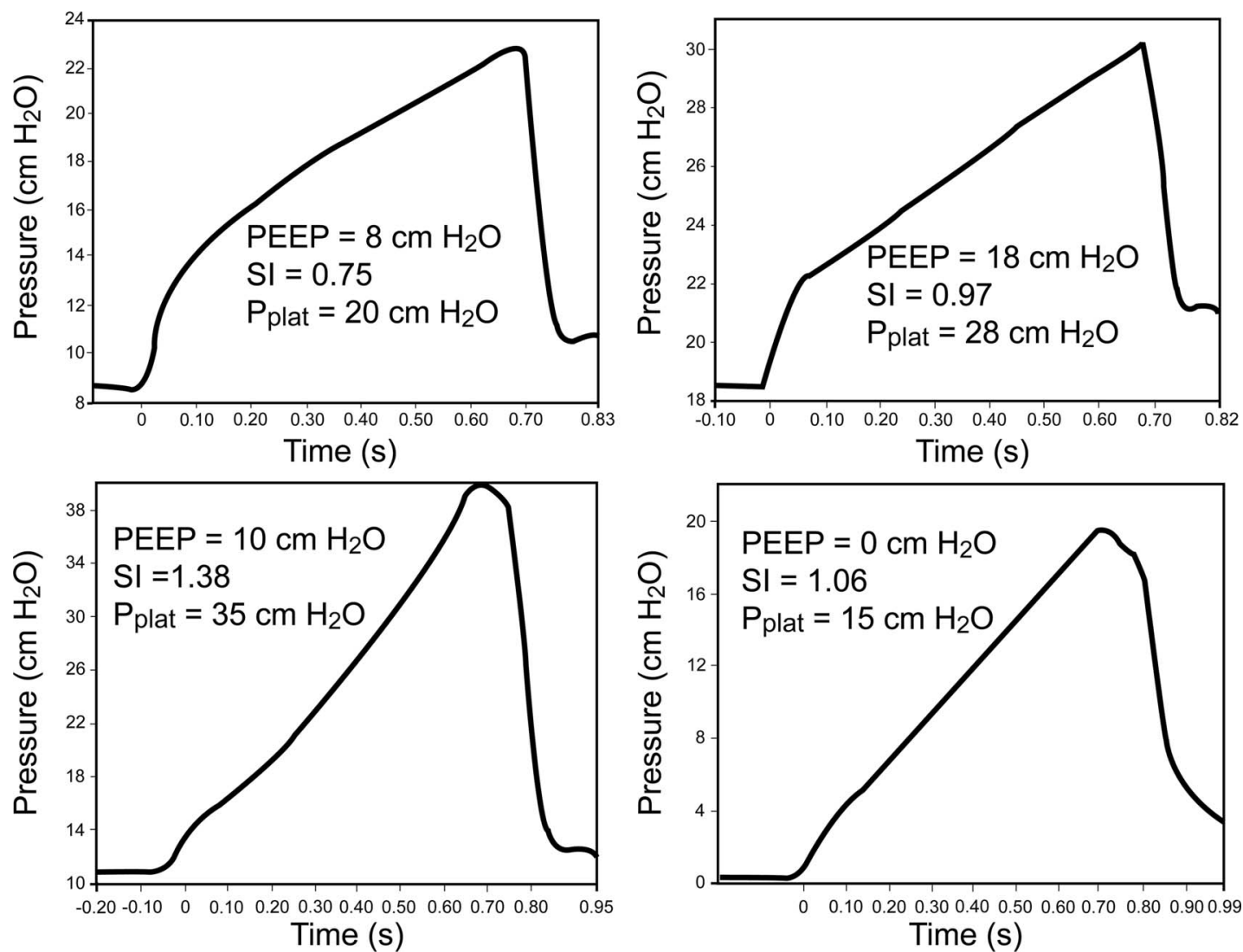

Fig. 7. Top: Stress index (SI) in a patient early in the course of ARDS. In this case, the stress index improved as PEEP was increased. Bottom: Stress index in a patient late in the course of ARDS. In this case, the SI improved as PEEP was decreased. $P_{\text {plat }}=$ plateau pressure. From References 10 and 79.

\section{Stress Index}

The stress index ${ }^{79}$ is based on the shape of the pressuretime curve during constant flow volume control ventilation (Fig. 7). A linear increase in pressure (stress index $=1$ ) suggests alveolar recruitment without overdistention. A decrease in compliance as the lungs are inflated (upward concavity, stress index $>1$ ) suggests overdistention, and the recommendation is to decrease PEEP, $\mathrm{V}_{\mathrm{T}}$, or both. An increase in compliance as the lungs are inflated (downward concavity, stress index $<1$ ) suggests tidal recruitment and the potential for additional recruitment, and the recommendation is to increase PEEP. The stress index can be determined by curve fitting and is incorporated into the software of one commercially available ventilator.

In 15 subjects with ARDS, Grasso et al ${ }^{64}$ randomly applied PEEP using the ARDS Network low PEEP/F $\mathrm{IO}_{2}$ table or stress index. $\mathrm{V}_{\mathrm{T}}$ was $6 \mathrm{~mL} / \mathrm{kg}$ in all subjects. In all subjects, the stress index demonstrated alveolar hyperinflation with the ARDS Network strategy. Thus, PEEP was lower with the stress index approach than with the ARDS Network approach. Compliance was also better with the stress index approach. Plasma concentrations of inflammatory mediators were significantly lower during the stress index approach. The results of this study suggest that, at least in these subjects, the ARDS Network low PEEP/ $/ \mathrm{F}_{2}$ table can contribute to overdistention.

In 30 subjects with ARDS, Huang et al ${ }^{80}$ randomly set PEEP according to stress index, oxygenation, compliance, or P-V curve. $\mathrm{V}_{\mathrm{T}}$ was set at $6 \mathrm{~mL} / \mathrm{kg}$, and all subjects were paralyzed. PEEP determined by stress index $\left(15.1 \pm 1.8 \mathrm{~cm} \mathrm{H}_{2} \mathrm{O}\right)$ was similar to that determined by oxygenation $\left(14.5 \pm 2.9 \mathrm{~cm} \mathrm{H}_{2} \mathrm{O}\right)$ but higher than that titrated by compliance $\left(11.3 \pm 2.5 \mathrm{~cm} \mathrm{H}_{2} \mathrm{O}\right)$ and $\mathrm{P}-\mathrm{V}$ curve $\left(12.9 \pm 1.6 \mathrm{~cm} \mathrm{H}_{2} \mathrm{O}\right)$.

In a physiologic study, Terragni et $\mathrm{al}^{7}$ examined the accuracy of $\mathrm{P}_{\text {plat }}$ and stress index to identify injurious ventilation in subjects with ARDS. Using CT to identify overdistention, they found that injurious ventilation was associated with a $\mathrm{P}_{\text {plat }}>25 \mathrm{~cm} \mathrm{H}_{2} \mathrm{O}$ and a stress index of $>1.05$. It is interesting to note that PEEP, on average, was higher in the setting of overdistention, although $\mathrm{V}_{\mathrm{T}}$ values were similar. The authors also found that bronchoalveolar lavage concentrations of inflammatory mediators were higher in subjects with overdistention. 


\section{Recruitment Maneuvers AND PEEP Titration}

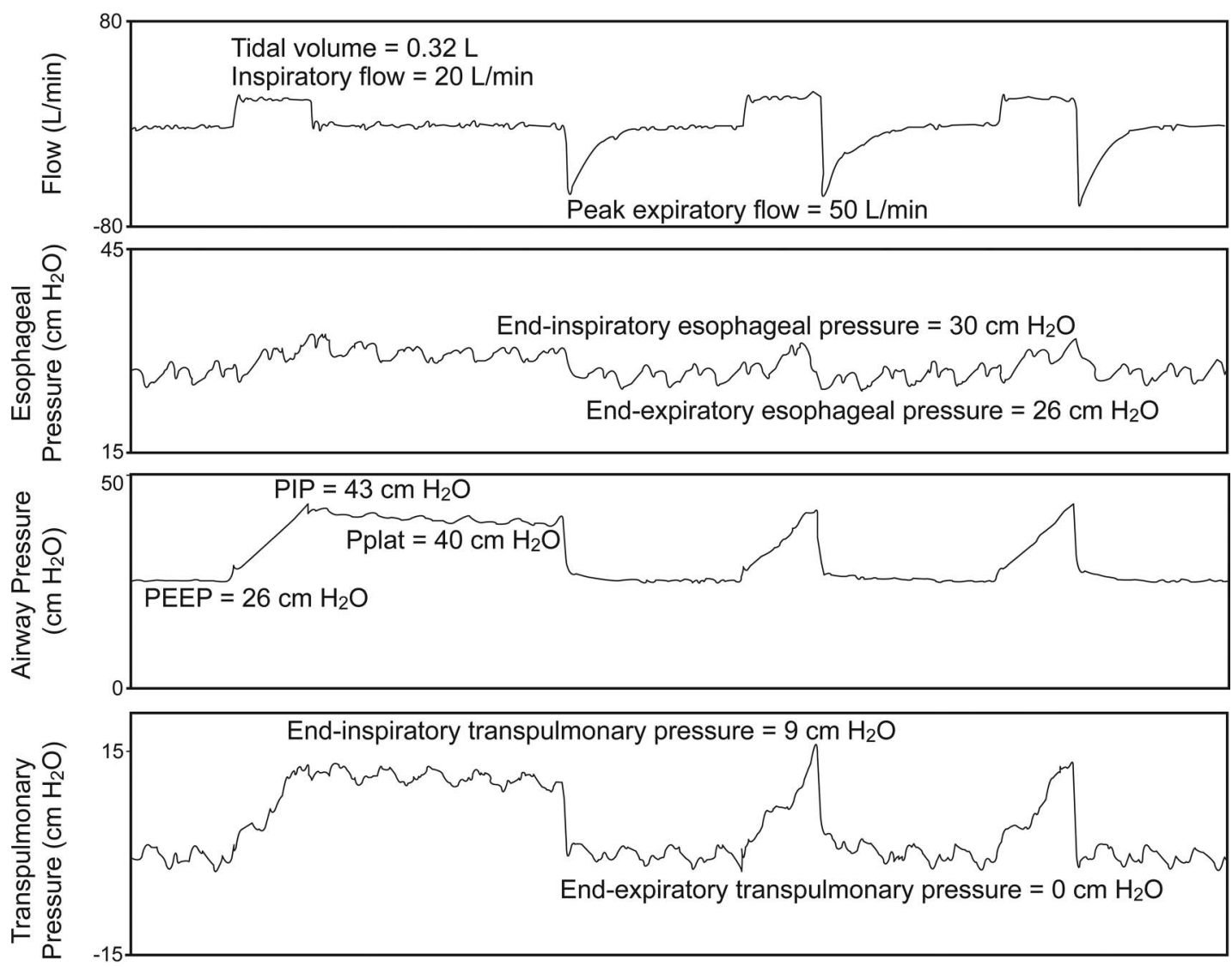

Fig. 8. Esophageal pressure, with airway pressure, can be used to determine end-inspiratory and end-expiratory transpulmonary pressure. In this example, PEEP is set so that the end-expiratory transpulmonary pressure is zero. See text for details. PIP $=$ peak inspiratory pressure; $\mathrm{P}_{\text {plat }}=$ plateau pressure. From Reference 79.

\section{Esophageal Manometry}

Chest wall compliance may be reduced in patients with ARDS. This can result in an increase in pleural pressure, and if pleural pressure is high relative to alveolar pressure, there is a potential for alveolar collapse. ${ }^{81}$ Thus, it may be desirable to set PEEP greater than end-expiratory pleural pressure. The use of an esophageal balloon to estimate pleural pressure has been advocated to allow a more precise setting of PEEP (Fig. 8). In a study by Talmor et al, ${ }^{65}$ 61 subjects with ARDS were randomly assigned to PEEP adjusted according to measurements of esophageal pressure or according to the ARDS Network low PEEP table. The strategy using esophageal pressure resulted in significantly greater oxygenation and compliance. A multi-center study is under way to determine whether this use of esophageal pressure to set PEEP improves patient outcomes (ClinicalTrials.gov registration NCT01681225). Regardless of whether esophageal manometry proves useful for routine setting of PEEP, it might be beneficial in selected patients, such as those with morbid obesity or abdominal hypertension. ${ }^{82}$

\section{Lung Volume}

The end-expiratory lung volume (EELV) can be measured during mechanical ventilation using helium dilution or nitrogen washout techniques. ${ }^{83-85}$ A modified nitrogen washout technique is available on one commercially available ventilator. If EELV is measured on 0 PEEP and then again after PEEP is added, it is possible to calculate strain, an important determinant of lung injury. This would seem attractive during PEEP titration. A PEEP-induced increase in EELV, however, might be the result of recruitment, or it might be due to overdistention of already open alveoli. Thus, EELV by itself may not be useful to assess PEEP response. The value of EELV to assess PEEP response might be improved if it is combined with measurement of compliance. ${ }^{86,87}$ Compliance can be used to estimate the increase in EELV if no recruitment occurs. For example, if the compliance is $30 \mathrm{~mL} / \mathrm{cm} \mathrm{H}_{2} \mathrm{O}$, one can predict an increase in EELV of $150 \mathrm{~mL}$ if PEEP is increased from $5 \mathrm{~cm} \mathrm{H}_{2} \mathrm{O}$ to $10 \mathrm{~cm} \mathrm{H}_{2} \mathrm{O}$. In this example, if EELV 


\section{Recruitment Maneuvers AND PEEP Titration}

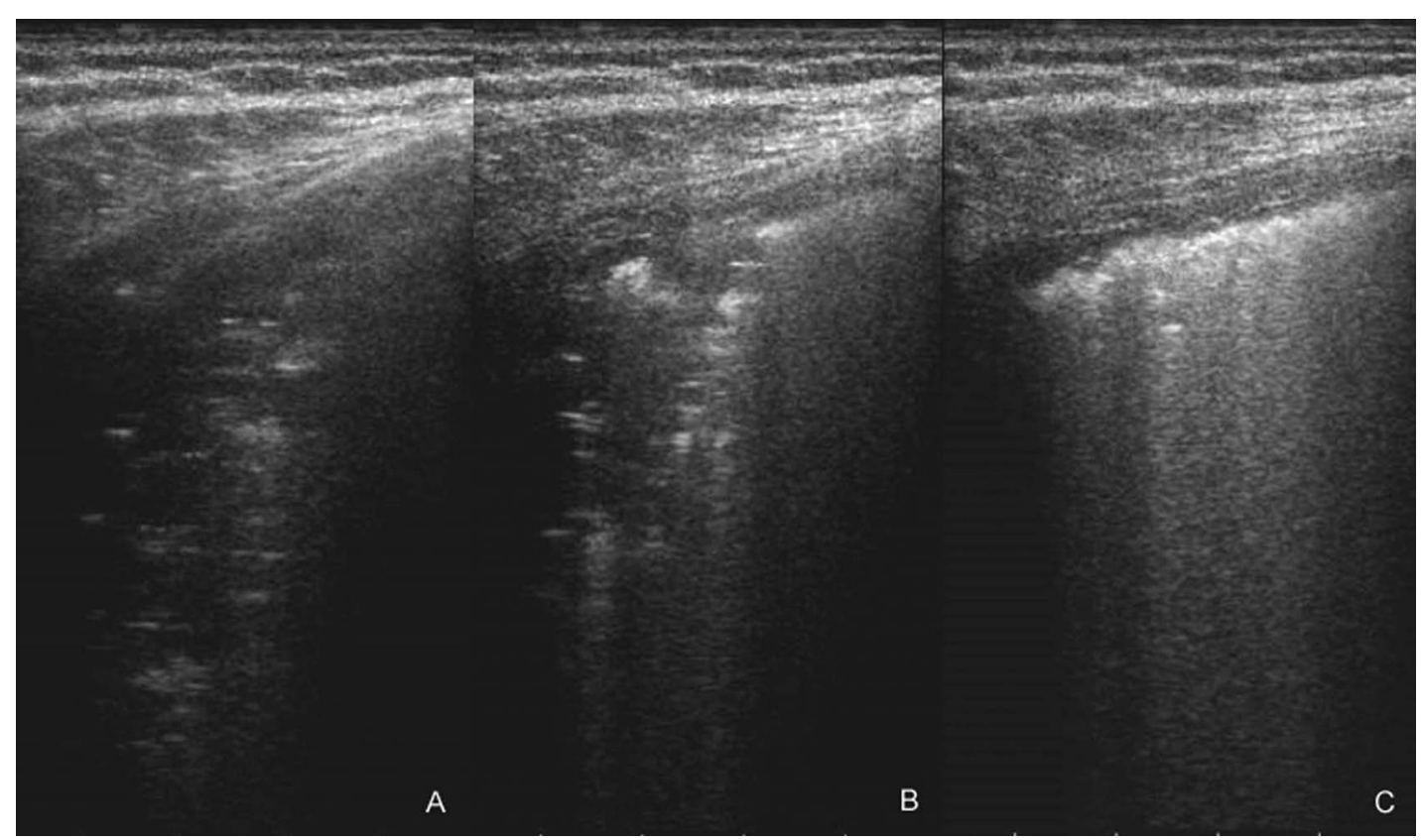

Fig. 9. Recruitment maneuver ultrasound evaluation. A: Consolidated parenchymal area in a patient with ARDS. B: The hyperreflectant air aspect reaching the pulmonary consolidation and the progressive reduction of its compactness. C: Recruitment. Consolidation is dimensionally reduced and partly replaced by normal air parenchyma, full of B lines, an expression of interstitial thickening. From Reference 97.

increases by $>150 \mathrm{~mL}$, the additional volume can be attributed to recruited volume.

\section{Imaging}

Imaging techniques hold promise for setting PEEP because, unlike evaluations of mechanics, they allow assessment of heterogeneity within the lungs. ${ }^{88-91} \mathrm{CT}$ imaging has long been the accepted standard for assessments of alveolar recruitment and overdistention. Digital chest radiography done at the bedside with PEEP of 5 and $15 \mathrm{~cm} \mathrm{H}_{2} \mathrm{O}$ might also be useful to detect recruited lung volume. ${ }^{92}$

Ultrasound uses an emission frequency of 5-7 MHz for visualization of the lung. The probe should have a small convex tip that can be easily placed on intercostal spaces to allow an acoustic window on the parenchyma. The ultrasound pattern corresponds to the degree of lung aeration. ${ }^{88,93-96}$ This allows the potential for the use of ultrasound to monitor the response to recruitment maneuvers and PEEP titration (Fig. 9). ${ }^{97}$ In 40 subjects with ARDS, Bouhemad et ${ }^{94}$ al compared $\mathrm{P}-\mathrm{V}$ curves and ultrasound at PEEP of 0 and $15 \mathrm{~cm} \mathrm{H}_{2} \mathrm{O}$. A significant correlation was found between PEEP-induced lung recruitment assessed by $\mathrm{P}-\mathrm{V}$ curves and ultrasound reaeration score, suggesting that PEEP-induced lung recruitment can be adequately estimated with bedside ultrasound. A limitation of lung ultrasound is that it cannot detect overdistention, and thus it should be combined with other assessments, such compliance.
EIT is a noninvasive, radiation-free monitoring tool that allows real-time imaging of ventilation. Electrical impedance tomography uses high frequency and low amplitude electrical currents, typically through 16 or 32 electrodes around the thorax, to obtain images of a cross section of the lungs..$^{98}$ Electrical impedance tomography has the potential for bedside use to estimate regional alveolar collapse and overdistention. ${ }^{98-103}$ To date, experience with electrical impedance tomography in North America is limited.

Lung ultrasound and electrical impedance tomography show promise as technologies to allow application of mechanical ventilation. Ultrasound technology is widely available in the ICU. Respiratory therapists should develop the skills to use lung ultrasound to assess real-time lung aeration and the response to changes in ventilator settings. Electrical impedance tomography is not yet widely available, but this is also a technology in which respiratory therapists can gain expertise.

\section{How Long to Wait Between Changes in PEEP}

A practical question at the bedside is how much time is necessary to assess a change in PEEP. If too little time is allowed, the effect of the change in PEEP will not be fully realized. On the other hand, if too much time is allowed, more time will be necessary for the full PEEP titration, and the patient will be potentially subjected to injurious ventilation due to inappropriate PEEP. 
Chiumello et al ${ }^{104,105}$ conducted a physiologic study to address this question. When PEEP was decreased, $\mathrm{P}_{\mathrm{aO}_{2}}$ and the other oxygenation-related variables significantly decreased within $5 \mathrm{~min}$ and remained unmodified in the following 55 min. When PEEP was increased, the $\mathrm{P}_{\mathrm{aO}_{2}}$ continuously rose, and equilibrium was not reached by 60 min. When PEEP was decreased, compliance was unchanged at $5 \mathrm{~min}$ but decreased over the next $55 \mathrm{~min}$. In the individual patients, the change of oxygenation-related variables and compliance at 5 min could predict the changes recorded after $60 \mathrm{~min}$. Thus, when doing a PEEP titration, changes in oxygenation and respiratory mechanics after 5 min might be used to judge the direction of change (improving or worsening), but the full effect might take $\geq 60$ min.

\section{Higher Versus Lower PEEP: The Evidence}

There have been 6 clinical trials that assessed the use of lower versus higher PEEP in subjects with ARDS. 19,50,51,59,63,65 In 2 studies, there was a significant mortality reduction in the group who received higher PEEP, but a higher PEEP was combined with a lower $\mathrm{V}_{\mathrm{T}}$, and therefore it is unknown whether the mortality benefit is attributable to higher PEEP. ${ }^{19,50}$ The ARDS Network and the Lung Open Ventilation study compared PEEP/F $\mathrm{IO}_{2}$ tables directing higher or lower PEEP, ${ }^{51,59}$ and the ExPress study ${ }^{63}$ compared lower PEEP versus a PEEP strategy based on compliance. Each of these 3 studies was negative for the primary outcome of mortality. There are several potential reasons why these 3 trials were negative: (1) perhaps a higher level of PEEP is not effective; (2) perhaps the methods used to set PEEP were not the correct approaches; (3) perhaps higher PEEP is not effective in unselected patients with ARDS but might be effective in patients with a higher potential for recruitment (Fig. 10); (4) perhaps these studies were underpowered to show a difference in outcome. ${ }^{10}$

The meta-analysis by Briel et al ${ }^{106}$ provides some insight. Using individual subject data from 3 trials, the mortality was $32.9 \%$ for subjects assigned to treatment with higher PEEP and $35.2 \%$ for subjects assigned to lower PEEP (adjusted relative risk 0.94, 95\% CI 0.86-1.04). However, treatment effects varied, depending on the severity of ARDS. In subjects with moderate and severe ARDS, the mortality was $34.1 \%$ in the higher-PEEP group and $39.1 \%$ in the lower-PEEP group (adjusted relative risk $0.90,95 \%$ CI $0.81-1.00)$. In subjects with mild ARDS, the mortality was $27.2 \%$ in the higherPEEP group and $19.4 \%$ in the lower-PEEP group (adjusted relative risk $1.37,95 \%$ CI $0.98-1.92$ ). This analysis suggests that treatment with lower PEEP should be used with mild ARDS, and higher PEEP should be used with moderate and severe ARDS $\left(\mathrm{P}_{\mathrm{aO}_{2}} / \mathrm{F}_{\mathrm{IO}_{2}}\right.$

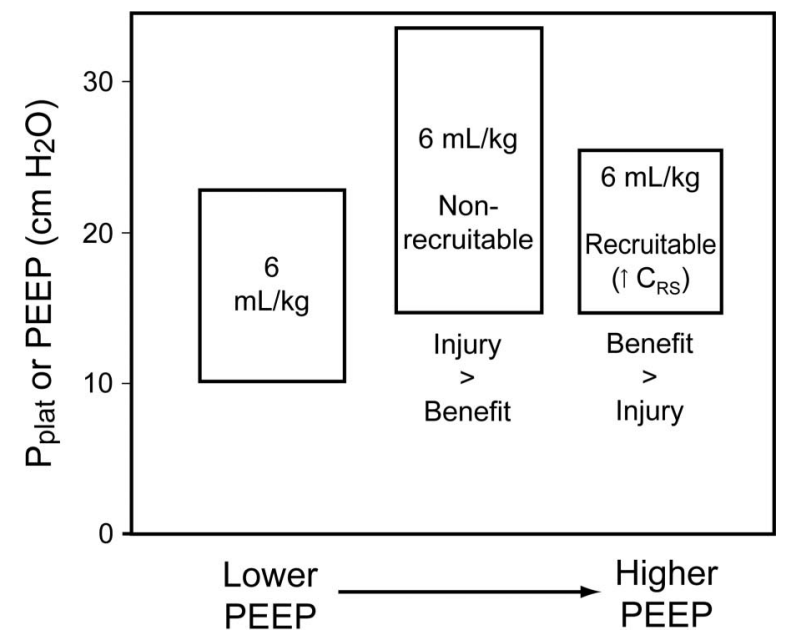

Fig. 10. Potential effects of an increase in PEEP. If the potential for recruitment is low, an increase in PEEP results in a large increase in plateau pressure $\left(P_{\text {plat }}\right)$ (increased driving pressure) to an unsafe level. In this case, the potential harm from overdistention probably outweighs any benefit resulting from increased alveolar recruitment. If the potential for recruitment is high, an increase in PEEP results in little increase in $P_{\text {plat. }}$ In this case, the potential benefit of increased PEEP probably outweighs the harm due to the small increase in $\mathrm{P}_{\text {plat. }}$. From Reference 10.

S200). Patients with moderate and severe ARDS likely have more potential for recruitment than patients with mild ARDS.

\section{Summary and Recommendations: PEEP}

1. PEEP should be selected as a balance between alveolar recruitment and overdistention.

2. PEEP of $<5 \mathrm{~cm} \mathrm{H}_{2} \mathrm{O}$ is probably harmful early in the course of ARDS.

3. Randomized controlled trials have failed to show a survival benefit for the use of higher versus lower levels of PEEP.

4. Post hoc analysis of randomized controlled trials and a strong physiologic rationale support lower levels of PEEP for mild ARDS and higher levels of PEEP for moderate and severe ARDS: 5-10 $\mathrm{cm} \mathrm{H}_{2} \mathrm{O}$ in mild ARDS, 10-15 $\mathrm{cm} \mathrm{H}_{2} \mathrm{O}$ in moderate ARDS, and 15$20 \mathrm{~cm} \mathrm{H}_{2} \mathrm{O}$ in severe ARDS. ${ }^{107}$

5. Evidence is not currently available to suggest that one approach to setting PEEP leads to better outcomes than other approaches.

6. In many hospitals, the PEEP/ $/ \mathrm{F}_{\mathrm{IO}_{2}}$ tables of the ARDS Network or best compliance can be used for PEEP selection; advanced methods, such as stress index, esophageal manometry, ultrasound, and electrical impedance tomography, can be used in hospitals with the necessary equipment and expertise. 


\section{Recruitment Maneuvers and PEEP Titration}

\section{Summary}

Alveolar recruitment is desirable if it can be achieved safely. If a recruitment maneuver is considered, the potential beneficial effects must be weighed against the potential for harm. PEEP titration should balance alveolar recruitment against overdistention. Rather than a best PEEP approach, Gattinoni ${ }^{107}$ suggests that we should think of a better PEEP approach as a reasonable compromise among oxygenation, hemodynamics, and cyclical opening and closing. Recruitment maneuvers and PEEP should be used within the context of lung protection and not just as a means of improving oxygenation.

\section{REFERENCES}

1. Gattinoni L, Pesenti A. The concept of "baby lung." Intensive Care Med 2005;31(6):776-784.

2. Slutsky AS, Ranieri VM. Ventilator-induced lung injury. N Engl J Med 2014;370(10):980.

3. Hubmayr RD. Perspective on lung injury and recruitment: a skeptical look at the opening and collapse story. Am J Respir Crit Care Med 2002;165(12):1647-1653.

4. The Acute Respiratory Distress Syndrome Network. Ventilation with lower tidal volumes as compared with traditional tidal volumes for acute lung injury and the acute respiratory distress syndrome. N Engl J Med 2000;342(18):1301-1308.

5. Needham DM, Colantuoni E, Mendez-Tellez PA, Dinglas VD, Sevransky JE, Dennison Himmelfarb CR, et al. Lung protective mechanical ventilation and two year survival in patients with acute lung injury: prospective cohort study. BMJ 2012;344:e2124.

6. Needham DM, Yang T, Dinglas VD, Mendez-Tellez PA, Shanholtz C, Sevransky JE, et al. Timing of low tidal volume ventilation and intensive care unit mortality in acute respiratory distress syndrome. A prospective cohort study. Am J Respir Crit Care Med 2015; 191(2):177-185.

7. Terragni PP, Filippini C, Slutsky AS, Birocco A, Tenaglia T, Grasso $\mathrm{S}$, et al. Accuracy of plateau pressure and stress index to identify injurious ventilation in patients with acute respiratory distress syndrome. Anesthesiology 2013;119(4):880-889.

8. Terragni PP, Rosboch G, Tealdi A, Corno E, Menaldo E, Davini O, et al. Tidal hyperinflation during low tidal volume ventilation in acute respiratory distress syndrome. Am J Respir Crit Care Med 2007;175(2):160-166.

9. Serpa Neto A, Cardoso SO, Manetta JA, Pereira VG, Espósito DC, Pasqualucci Mde O, et al. Association between use of lung-protective ventilation with lower tidal volumes and clinical outcomes among patients without acute respiratory distress syndrome: a metaanalysis. JAMA 2012;308(16):1651-1659.

10. Hess DR. Approaches to conventional mechanical ventilation of the patient with acute respiratory distress syndrome. Respir Care 2011; 56(10):1555-1572.

11. Hess DR. Ventilatory strategies in severe acute respiratory failure. Semin Respir Crit Care Med 2014;35(4):418-430.

12. Ramnath VR, Hess DR, Thompson BT. Conventional mechanical ventilation in acute lung injury and acute respiratory distress syndrome. Clin Chest Med 2006;27(4):601-613; abstract viii.

13. Gattinoni L, Carlesso E, Caironi P. Stress and strain within the lung. Curr Opin Crit Care 2012;18(1):42-47.

14. Mead J, Takishima T, Leith D. Stress distribution in lungs: a model of pulmonary elasticity. J Appl Physiol 1970;28(5):596-608.
15. Gattinoni L, Caironi P, Cressoni M, Chiumello D, Ranieri VM, Quintel M, et al. Lung recruitment in patients with the acute respiratory distress syndrome. N Engl J Med 2006;354(17):1775-1786.

16. Villar J, Pérez-Méndez L, López J, Belda J, Blanco J, Saralegui I, et al. An early PEEP/F $/ \mathrm{IO}_{2}$ trial identifies different degrees of lung injury in patients with acute respiratory distress syndrome. Am J Respir Crit Care Med 2007;176(8):795-804.

17. Chiumello D, Cressoni M, Carlesso E, Caspani ML, Marino A, Gallazzi E, et al. Bedside selection of positive end-expiratory pressure in mild, moderate, and severe acute respiratory distress syndrome. Crit Care Med 2014;42(2):252-264.

18. Hess DR, Bigatello LM. Lung recruitment: the role of recruitment maneuvers. Respir Care 2002;47(3):308-317; discussion 317-318.

19. Amato MB, Barbas CS, Medeiros DM, Magaldi RB, Schettino GP, Lorenzi-Filho G, et al. Effect of a protective-ventilation strategy on mortality in the acute respiratory distress syndrome. N Engl J Med 1998;338(6):347-354.

20. Brower RG, Morris A, MacIntyre N, Matthay MA, Hayden D, Thompson T, et al. Effects of recruitment maneuvers in patients with acute lung injury and acute respiratory distress syndrome ventilated with high positive end-expiratory pressure. Crit Care Med 2003;31(11):2592-2597.

21. Meade MO, Cook DJ, Griffith LE, Hand LE, Lapinsky SE, Stewart TE, et al. A study of the physiologic responses to a lung recruitment maneuver in acute lung injury and acute respiratory distress syndrome. Respir Care 2008;53(11):1441-1449.

22. Fan E, Checkley W, Stewart TE, Muscedere J, Lesur O, Granton JT, et al. Complications from recruitment maneuvers in patients with acute lung injury: secondary analysis from the lung open ventilation study. Respir Care 2012;57(11):1842-1849.

23. Arnal JM, Paquet J, Wysocki M, Demory D, Donati S, Granier I, et al. Optimal duration of a sustained inflation recruitment maneuver in ARDS patients. Intensive Care Med 2011;37(10):1588-1594.

24. Kacmarek RM, Villar J. Management of refractory hypoxemia in ARDS. Minerva Anestesiol 2013;79(10):1173-1179.

25. Borges JB, Okamoto VN, Matos GF, Caramez MP, Arantes PR, Barros F, et al. Reversibility of lung collapse and hypoxemia in early acute respiratory distress syndrome. Am J Respir Crit Care Med 2006;174(3):268-278.

26. Girgis K, Hamed H, Khater Y, Kacmarek RM. A decremental PEEP trial identifies the PEEP level that maintains oxygenation after lung recruitment. Respir Care 2006;51(10):1132-1139.

27. Toth I, Leiner T, Mikor A, Szakmany T, Bogar L, Molnar Z. Hemodynamic and respiratory changes during lung recruitment and descending optimal positive end-expiratory pressure titration in patients with acute respiratory distress syndrome. Crit Care Med 2007; 35(3):787-793.

28. Fengmei G, Jin C, Songqiao L, Congshan Y, Yi Y. Dead space fraction changes during PEEP titration following lung recruitment in patients with ARDS. Respir Care 2012;57(10):1578-1585.

29. Marini JJ. Recruitment by sustained inflation: time for a change. Intensive Care Med 2011;37(10):1572-1574.

30. Froese AB, Bryan AC. Effects of anesthesia and paralysis on diaphragmatic mechanics in man. Anesthesiology 1974;41(3):242-255.

31. Maung AA, Schuster KM, Kaplan LJ, Ditillo MF, Piper GL, Maerz LL, et al. Compared to conventional ventilation, airway pressure release ventilation may increase ventilator days in trauma patients. J Trauma Acute Care Surg 2012;73(2):507-510.

32. Maxwell RA, Green JM, Waldrop J, Dart BW, Smith PW, Brooks $\mathrm{D}$, et al. A randomized prospective trial of airway pressure release ventilation and low tidal volume ventilation in adult trauma patients with acute respiratory failure. J Trauma 2010;69(3):501-510; discussion 511 . 


\section{Recruitment Maneuvers and PEEP Titration}

33. Varpula T, Valta P, Niemi R, Takkunen O, Hynynen M, Pettilä VV. Airway pressure release ventilation as a primary ventilatory mode in acute respiratory distress syndrome. Acta Anaesthesiol Scand 2004;48(6):722-731.

34. Richard JC, Lyazidi A, Akoumianaki E, Mortaza S, Cordioli RL, Lefebvre JC, et al. Potentially harmful effects of inspiratory synchronization during pressure preset ventilation. Intensive Care Med 2013;39(11):2003-2010.

35. Young D, Lamb SE, Shah S, MacKenzie I, Tunnicliffe W, Lall R, et al. High-frequency oscillation for acute respiratory distress syndrome. N Engl J Med 2013;368(9):806-813.

36. Ferguson ND, Cook DJ, Guyatt GH, Mehta S, Hand L, Austin P, et al. High-frequency oscillation in early acute respiratory distress syndrome. N Engl J Med 2013;368(9):795-805.

37. Huang CT, Lin HH, Ruan SY, Lee MS, Tsai YJ, Yu CJ. Efficacy and adverse events of high-frequency oscillatory ventilation in adult patients with acute respiratory distress syndrome: a meta-analysis. Crit Care 2014;18(3):R102.

38. Foti G, Cereda M, Sparacino ME, De Marchi L, Villa F, Pesenti A. Effects of periodic lung recruitment maneuvers on gas exchange and respiratory mechanics in mechanically ventilated acute respiratory distress syndrome (ARDS) patients. Intensive Care Med 2000; 26(5):501-507.

39. Patroniti N, Foti G, Cortinovis B, Maggioni E, Bigatello LM, Cereda M, Pesenti A. Sigh improves gas exchange and lung volume in patients with acute respiratory distress syndrome undergoing pressure support ventilation. Anesthesiology 2002;96(4):788-794.

40. Pelosi P, Cadringher P, Bottino N, Panigada M, Carrieri F, Riva E, et al. Sigh in acute respiratory distress syndrome. Am J Respir Crit Care Med 1999;159(3):872-880.

41. Pelosi P, Chiumello D, Calvi E, Taccone P, Bottino N, Panigada M, et al. Effects of different continuous positive airway pressure devices and periodic hyperinflations on respiratory function. Crit Care Med 2001;29(9):1683-1689.

42. Mauri T, Eronia N, Abbruzzese C, Marcolin R, Coppadoro A, Spadaro $\mathrm{S}$, et al. Effects of sigh on regional lung strain and ventilation heterogeneity in acute respiratory failure patients undergoing assisted mechanical ventilation. Crit Care Med 2015;43(9);18231831.

43. Gattinoni L, Taccone P, Carlesso E, Marini JJ. Prone position in acute respiratory distress syndrome. Rationale, indications, and limits. Am J Respir Crit Care Med 2013;188(11):1286-1293.

44. Guérin C. Prone position. Curr Opin Crit Care 2014;20(1):92-97.

45. Guerin C, Baboi L, Richard JC. Mechanisms of the effects of prone positioning in acute respiratory distress syndrome. Intensive Care Med 2014;40(11):1634-1642.

46. Mentzelopoulos SD, Roussos C, Zakynthinos SG. Prone position reduces lung stress and strain in severe acute respiratory distress syndrome. Eur Respir J 2005;25(3):534-544.

47. Guérin C, Reignier J, Richard JC, Beuret P, Gacouin A, Boulain T, et al. Prone positioning in severe acute respiratory distress syndrome. N Engl J Med 2013;368(23):2159-2168

48. Beitler JR, Shaefi S, Montesi SB, Devlin A, Loring SH, Talmor D, Malhotra A. Prone positioning reduces mortality from acute respiratory distress syndrome in the low tidal volume era: a meta-analysis. Intensive Care Med 2014;40(3):332-341.

49. Lee JM, Bae W, Lee YJ, Cho YJ. The efficacy and safety of prone positional ventilation in acute respiratory distress syndrome: updated study-level meta-analysis of 11 randomized controlled trials. Crit Care Med 2014;42(5):1252-1262.

50. Villar J, Kacmarek RM, Pérez-Méndez L, Aguirre-Jaime A. A high positive end-expiratory pressure, low tidal volume ventilatory strategy improves outcome in persistent acute respiratory distress syn- drome: a randomized, controlled trial. Crit Care Med 2006;34(5): 1311-1318.

51. Meade MO, Cook DJ, Guyatt GH, Slutsky AS, Arabi YM, Cooper DJ, et al. Ventilation strategy using low tidal volumes, recruitment maneuvers, and high positive end-expiratory pressure for acute lung injury and acute respiratory distress syndrome: a randomized controlled trial. JAMA 2008;299(6):637-645.

52. Hodgson CL, Tuxen DV, Davies AR, Bailey MJ, Higgins AM, Holland AE, et al. A randomised controlled trial of an open lung strategy with staircase recruitment, titrated PEEP and targeted low airway pressures in patients with acute respiratory distress syndrome. Crit Care 2011;15(3):R133.

53. Suzumura EA, Figueiró M, Normilio-Silva K, Laranjeira L, Oliveira C, Buehler AM, et al. Effects of alveolar recruitment maneuvers on clinical outcomes in patients with acute respiratory distress syndrome: a systematic review and meta-analysis. Intensive Care Med 2014;40(9):1227-1240.

54. Ashbaugh DG, Bigelow DB, Petty TL, Levine BE. Acute respiratory distress in adults. Lancet 1967;2(7511):319-323.

55. Downs JB, Klein EF Jr, Modell JH. The effect of incremental PEEP on $\mathrm{PaO} 2$ in patients with respiratory failure. Anesth Analg 1973; 52(2):210-215.

56. Kirby RR, Downs JB, Civetta JM, Modell JH, Dannemiller FJ, Klein EF, Hodges M. High level positive end expiratory pressure (PEEP) in acute respiratory insufficiency. Chest 1975;67(2):156163.

57. Ferguson ND, Frutos-Vivar F, Esteban A, Anzueto A, Alía I, Brower $\mathrm{RG}$, et al. Airway pressures, tidal volumes, and mortality in patients with acute respiratory distress syndrome. Crit Care Med 2005;33(1): 21-30.

58. Goligher EC, Kavanagh BP, Rubenfeld GD, Adhikari NK, Pinto R, Fan E, et al. Oxygenation response to positive end-expiratory pressure predicts mortality in acute respiratory distress syndrome. A secondary analysis of the LOVS and ExPress trials. Am J Respir Crit Care Med 2014;190(1):70-76.

59. Brower RG, Lanken PN, MacIntyre N, Matthay MA, Morris A, Ancukiewicz M, et al. Higher versus lower positive end-expiratory pressures in patients with the acute respiratory distress syndrome. N Engl J Med 2004;351(4):327-336.

60. Arnal JM, Garnero A, Novonti D, Demory D, Ducros L, Berric A, et al. Feasibility study on full closed-loop control ventilation (IntelliVent-ASV) in ICU patients with acute respiratory failure: a prospective observational comparative study. Crit Care 2013;17(5): R196.

61. Arnal JM, Wysocki M, Novotni D, Demory D, Lopez R, Donati S, et al. Safety and efficacy of a fully closed-loop control ventilation (IntelliVent-ASV) in sedated ICU patients with acute respiratory failure: a prospective randomized crossover study. Intensive Care Med 2012;38(5):781-787.

62. Clavieras N, Wysocki M, Coisel Y, Galia F, Conseil M, Chanques $\mathrm{G}$, et al. Prospective randomized crossover study of a new closedloop control system versus pressure support during weaning from mechanical ventilation. Anesthesiology 2013;119(3):631-641.

63. Mercat A, Richard JC, Vielle B, Jaber S, Osman D, Diehl JL, et al. Positive end-expiratory pressure setting in adults with acute lung injury and acute respiratory distress syndrome: a randomized controlled trial. JAMA 2008;299(6):646-655.

64. Grasso S, Stripoli T, De Michele M, Bruno F, Moschetta M, Angelelli G, et al. ARDSnet ventilatory protocol and alveolar hyperinflation: role of positive end-expiratory pressure. Am J Respir Crit Care Med 2007;176(8):761-767.

65. Talmor D, Sarge T, Malhotra A, O'Donnell CR, Ritz R, Lisbon A, et al. Mechanical ventilation guided by esophageal pressure in acute lung injury. N Engl J Med 2008;359(20):2095-2104. 


\section{Recruitment Maneuvers and PEEP Titration}

66. Suter PM, Fairley B, Isenberg MD. Optimum end-expiratory airway pressure in patients with acute pulmonary failure. N Engl J Med 1975;292(6):284-289.

67. Murray IP, Modell JH, Gallagher TJ, Banner MJ. Titration of PEEP by the arterial minus end-tidal carbon dioxide gradient. Chest 1984; 85(1):100-104

68. Blanch L, Fernández R, Benito S, Mancebo J, Net A. Effect of PEEP on the arterial minus end-tidal carbon dioxide gradient. Chest 1987;92(3):451-454.

69. Jardin F, Genevray B, Pazin M, Margairaz A. Inability to titrate PEEP in patients with acute respiratory failure using end-tidal carbon dioxide measurements. Anesthesiology 1985;62(4):530-533.

70. Anderson CT, Breen PH. Carbon dioxide kinetics and capnography during critical care. Crit Care 2000;4(4):207-215.

71. Pintado MC, de Pablo R, Trascasa M, Milicua JM, Rogero S, Daguerre $\mathrm{M}$, et al. Individualized PEEP setting in subjects with ARDS: a randomized controlled pilot study. Respir Care 2013; 58(9):1416-1423.

72. Amato MB, Meade MO, Slutsky AS, Brochard L, Costa EL, Schoenfeld DA, et al. Driving pressure and survival in the acute respiratory distress syndrome. N Engl J Med 2015;372(8):747-755.

73. Albaiceta GM, Blanch L, Lucangelo U. Static pressure-volume curves of the respiratory system: were they just a passing fad? Curr Opin Crit Care 2008;14(1):80-86.

74. Harris RS. Pressure-volume curves of the respiratory system. Respir Care 50(1):78-98, 2005; discussion 98-79.

75. Blanch L, López-Aguilar J, Villagrá A. Bedside evaluation of pressure-volume curves in patients with acute respiratory distress syndrome. Curr Opin Crit Care 2007;13(3):332-337.

76. Harris RS, Hess DR, Venegas JG. An objective analysis of the pressure-volume curve in the acute respiratory distress syndrome. Am J Respir Crit Care Med 2000;161(2 Pt 1):432-439.

77. Owens RL, Hess DR, Malhotra A, Venegas JG, Harris RS. Effect of the chest wall on pressure-volume curve analysis of acute respiratory distress syndrome lungs. Crit Care Med 2008;36(11):29802985.

78. Hickling KG. The pressure-volume curve is greatly modified by recruitment: a mathematical model of ARDS lungs. Am J Respir Crit Care Med 1998;158(1):194-202.

79. Hess DR. Respiratory mechanics in mechanically ventilated patients. Respir Care 2014;59(11):1773-1794.

80. Huang Y, Yang Y, Chen Q, Liu S, Liu L, Pan C, et al. Pulmonary acute respiratory distress syndrome: positive end-expiratory pressure titration needs stress index. J Surg Res 2013;185(1):347-352.

81. Loring SH, O’Donnell CR, Behazin N, Malhotra A, Sarge T, Ritz $\mathrm{R}$, et al. Esophageal pressures in acute lung injury: do they represent artifact or useful information about transpulmonary pressure, chest wall mechanics, and lung stress? J Appl Physiol 2010;108(3): 515-522.

82. Talmor DS, Fessler HE. Are esophageal pressure measurements important in clinical decision-making in mechanically ventilated patients? Respir Care 2010 ;55(2):162-172; discussion 172-164.

83. Dellamonica J, Lerolle N, Sargentini C, Beduneau G, Di Marco F, Mercat A, et al. Accuracy and precision of end-expiratory lungvolume measurements by automated nitrogen washout/washin technique in patients with acute respiratory distress syndrome. Crit Care 2011;15(6):R294.

84. Chiumello D, Cressoni M, Chierichetti M, Tallarini F, Botticelli M, Berto V, et al. Nitrogen washout/washin, helium dilution and computed tomography in the assessment of end expiratory lung volume. Crit Care 2008;12(6):R150.

85. Branson RD, Johannigman JA. Innovations in mechanical ventilation. Respir Care 2009;54(7):933-947.
86. Bikker IG, van Bommel J, Reis Miranda D, Bakker J, Gommers D. End-expiratory lung volume during mechanical ventilation: a comparison with reference values and the effect of positive end-expiratory pressure in intensive care unit patients with different lung conditions. Crit Care 2008;12(6):R145.

87. Dellamonica J, Lerolle N, Sargentini C, Beduneau G, Di Marco F, Mercat A, et al. PEEP-induced changes in lung volume in acute respiratory distress syndrome: two methods to estimate alveolar recruitment. Intensive Care Med 2011;37(10):1595-1604.

88. Chiumello D, Froio S, Bouhemad B, Camporota L, Coppola S. Clinical review: Lung imaging in acute respiratory distress syndrome patients-an update. Crit Care 2013;17(6):243.

89. Chiumello D, Marino A, Brioni M, Menga F, Cigada I, Lazzerini $\mathrm{M}$, et al. Visual anatomical lung CT scan assessment of lung recruitability. Intensive Care Med 2013;39(1):66-73.

90. Gattinoni L, Caironi P, Valenza F, Carlesso E. The role of CT-scan studies for the diagnosis and therapy of acute respiratory distress syndrome. Clin Chest Med 2006;27(4):559-570; abstract vii.

91. Rouby JJ, Puybasset L, Nieszkowska A, Lu Q. Acute respiratory distress syndrome: lessons from computed tomography of the whole lung. Crit Care Med 2003;31(4 Suppl):S285-S295.

92. Wallet F, Delannoy B, Haquin A, Debord S, Leray V, Bourdin $\mathrm{G}$, et al. Evaluation of recruited lung volume at inspiratory plateau pressure with PEEP using bedside digital chest $\mathrm{x}$-ray in patients with acute lung injury/ARDS. Respir Care 2013;58(3): 416-423.

93. Arbelot C, Ferrari F, Bouhemad B, Rouby JJ. Lung ultrasound in acute respiratory distress syndrome and acute lung injury. Curr Opin Crit Care 2008;14(1):70-74.

94. Bouhemad B, Brisson H, Le-Guen M, Arbelot C, Lu Q, Rouby JJ. Bedside ultrasound assessment of positive end-expiratory pressureinduced lung recruitment. Am J Respir Crit Care Med 2011;183(3): 341-347.

95. Bouhemad B, Mongodi S, Via G, Rouquette I. Ultrasound for "lung monitoring" of ventilated patients. Anesthesiology 2015;122(2): 437-447.

96. Bouhemad B, Zhang M, Lu Q, Rouby JJ. Clinical review: Bedside lung ultrasound in critical care practice. Crit Care 2007;11(1):205.

97. Gardelli G, Feletti F, Nanni A, Mughetti M, Piraccini A, Zompatori M. Chest ultrasonography in the ICU. Respir Care 2012;57(5):773781.

98. Costa EL, Lima RG, Amato MB. Electrical impedance tomography. Curr Opin Crit Care 2009;15(1):18-24.

99. Costa EL, Borges JB, Melo A, Suarez-Sipmann F, Toufen C Jr, Bohm SH, Amato MB. Bedside estimation of recruitable alveolar collapse and hyperdistension by electrical impedance tomography. Intensive Care Med 2009;35(6):1132-1137.

100. Bikker IG, Leonhardt S, Bakker J, Gommers D. Lung volume calculated from electrical impedance tomography in ICU patients at different PEEP levels. Intensive Care Med 2009;35(8):1362-1367.

101. Bikker IG, Leonhardt S, Reis Miranda D, Bakker J, Gommers D. Bedside measurement of changes in lung impedance to monitor alveolar ventilation in dependent and non-dependent parts by electrical impedance tomography during a positive end-expiratory pressure trial in mechanically ventilated intensive care unit patients. Crit Care 2010;14(3):R100.

102. Bikker IG, Preis C, Egal M, Bakker J, Gommers D. Electrical impedance tomography measured at two thoracic levels can visualize the ventilation distribution changes at the bedside during a decremental positive end-expiratory lung pressure trial. Crit Care 2011;15(4):R193.

103. Zhao Z, Steinmann D, Frerichs I, Guttmann J, Möller K. PEEP titration guided by ventilation homogeneity: a feasibility study using electrical impedance tomography. Crit Care 2010;14(1):R8. 


\section{Recruitment Maneuvers And PEEP Titration}

104. Chiumello D, Coppola S, Froio S, Mietto C, Brazzi L, Carlesso E, Gattinoni L. Time to reach a new steady state after changes of positive end expiratory pressure. Intensive Care Med 2013;39(8): 1377-1385.

105. Brower RG. Time to reach a new equilibrium after changes in PEEP in acute respiratory distress syndrome patients. Intensive Care Med 2013;39(11):2053-2055.
106. Briel M, Meade M, Mercat A, Brower RG, Talmor D, Walter SD, et al. Higher vs lower positive end-expiratory pressure in patients with acute lung injury and acute respiratory distress syndrome: systematic review and meta-analysis. JAMA 2010;303(9):865-873.

107. Gattinoni L, Carlesso E, Cressoni M. Selecting the "right" positive end-expiratory pressure level. Curr Opin Crit Care 2015;21(1):5057. 